Review

\title{
Managing Phenol Contents in Crop Plants by Phytochemical Farming and Breeding - Visions and Constraints
}

\section{Dieter Treutter}

Unit Fruit Science, Center of Life and Food Sciences Weihenstephan, Technische Universität München, Dürnast 2, D-85354 Freising, Germany; E-Mail: dieter.treutter@wzw.tum.de;

Tel.: +49-8161-713-753

Received: 15 January 2010; in revised form: 2 February 2010 / Accepted: 3 February 2010 / Published: 2 March 2010

\begin{abstract}
Two main fields of interest form the background of actual demand for optimized levels of phenolic compounds in crop plants. These are human health and plant resistance to pathogens and to biotic and abiotic stress factors. A survey of agricultural technologies influencing the biosynthesis and accumulation of phenolic compounds in crop plants is presented, including observations on the effects of light, temperature, mineral nutrition, water management, grafting, elevated atmospheric $\mathrm{CO}_{2}$, growth and differentiation of the plant and application of elicitors, stimulating agents and plant activators. The underlying mechanisms are discussed with respect to carbohydrate availability, trade-offs to competing demands as well as to regulatory elements. Outlines are given for genetic engineering and plant breeding. Constraints and possible physiological feedbacks are considered for successful and sustainable application of agricultural techniques with respect to management of plant phenol profiles and concentrations.
\end{abstract}

Keywords: flavonoids; phenylpropanoids; elicitor; stress; agricultural technology; apple; tomato; strawberry; lettuce; grapevine

\section{Introduction}

It was about 15 years ago that a booming interest in phenolic compounds, i.e., phenylpropanoids and flavonoids, started among scientists from varying research fields. This was catalyzed by an increasing popularity of the potential benefits of that class of secondary plant metabolites for human 
health, and this ongoing phenomenon was triggered by some key publications [1,2] reflecting the change in appraisement of the physiology of these natural ingredients of plant foods. From a pharmaceutical point of view the effects of flavonoids on mammalian cells were extensively reviewed by Middleton et al. [3] summarizing the scientific activities at that time. They listed the interactions of flavonoids with mammalian enzyme systems, the modulatory role of flavonoids in inflammatory processes, the action of flavonoids as antiviral, antitoxic, cytoprotective and antioxidant compounds. Middleton et al. [3] also discussed the relation of flavonoids to coronary vascular diseases, to vitamin $\mathrm{C}$ and to cancer. The gene regulatory activity of flavonoid-rich plant extracts was highlighted by Gohil and Packer [4]. The scientific progress in relating these phenolic pharmaceuticals to nutrition may have been started much earlier with the work of Szent-Györgyi's group who published the vitamin-like impact of pepper flavonoids [5]. Later on, all flavonoids with an effect on capillary permeability were subsumed as P-factors [6]. Pros and cons of these compounds in our diet were reviewed by Pierpoint [7] and Rogers [8], but are still a matter of debate [9-12]. The rising enthusiasm for these bioactive compounds, now also called nutraceuticals [13] is culminating in a huge number of scientific and even popular publications dealing with their health beneficial aspects. Fruits, vegetables and other crop plants seem to compete for a top ranking. Which may be the best: grape? cranberry? bilberry? apple? onion? tomato? pomegranate? green tea? soybean? buckwheat? carrot? artichoke? plum?...?

Based on the increasing knowledge of the biological activities of secondary plant constituents a number of commercial products have been introduced as food additives claiming health promoting properties and intending to counterbalance nutritional deficits of the Western diet as compared to Asian or Mediterranean food considered to be rich in phenolic compounds. Prominent examples are products containing grape seed meal or extracts. The respective bioactive components are catechins and proanthocyanidins [14], the latter are also called OPC (=oligomeric proanthocyanidins). In an example of commercial OPC-pellets high concentrations of monomeric catechins $(10 \mathrm{mg} / \mathrm{g})$ and soluble proanthocyanidins $(15 \mathrm{mg} / \mathrm{g}$ ) were estimated by HPLC-analysis (Treutter unpublished). Bread with grape seed additive contained despite of the heating 0.5 to $1.5 \mathrm{mg} / \mathrm{g}$ monomeric catechins and 0.2 to $0.5 \mathrm{mg} / \mathrm{g}$ proanthocyanidins (Treutter unpublished). Some food additives such as "Regulates" containing a wealth of phenolic compounds were analyzed more in detail and their antioxidant properties and immune modulating effects were demonstrated [15]. Within that context, it should be mentioned that there is an increasing interest in agricultural by-products which may be valuable as sources for bioactive compounds [16].

Some beverages are promoted as being of health promoting value because of their phenolic contents. A famous example is red wine with its phenolic constituents anthocyanins, proanthocyanidins and the stilbene resveratrol [17] considered to be responsible for the often cited "French paradox" which indicates a negative correlation between the wine consumed and the incidence of coronary heart disease [18]. The beneficial value of fruit juices is well accepted and attributed to various flavonoids (anthocyanins, flavonols, catechins and proanthocyanidins, phenylpropanoids). Intensively studied examples are apple juices [19-21], cranberry [22], black choke berry (Aronia melanocarpa) [23] pomegranate [24]. Efforts were made to increase the bioactive xanthohumol from hops in a German beer [25].

The profitable commercial use of phenolic compounds claiming their health benefits anticipate exact scientifically based knowledge about the daily intake being beneficial or essential or at least 
advisable for humans. This situation was critically reviewed by [26] who detailed facts and fiction with respect to nutraceuticals. Furthermore, despite consumers' general acceptance of the health benefits of, for instance, flavonoids, the need to enhance the intake of phenolic compounds may be questioned. This is described as result of a study on consumer perceptions of flavonoids [27].

The contribution of some phenolic compounds to taste properties of plant food is known for the astringent mouth-feel due to condensed and hydrolysable tannins (proanthocyanidins, gallotannins, ellagitannis). Prominent examples of fruits are cider apples [28] and persimmon [28]. However, a certain amount of tannin-like components may be desirable for optimal taste of some beverages [30]. Apple juice producers in some regions of Germany use the juice of the proanthocyanidin rich service tree fruits ("Speierling", Sorbus domestica) as a taste improving additive [31]. Recently, ethyl esters of hydroxybenzoic acids and hydroxycinnamic acids were identified as bitter compounds in wine [32]. Other phenolic compounds than tannins are considered responsible for the special organoleptic properties of olive oil, as well as its resistance to autoxidation [33].

Condensed tannins influence palatability and nutritive value of legumes [34] and protect ruminant animals against pasture bloat [35]. In a broad overview Mueller-Harvey [36] attempted to unravel the role of tannins in animal nutrition and examined the veterinary effects of these phenolic constituents of fodder plants. The legume sainfoin (Onobrychis viciifolia) is a good example for a pasture crop rich in diverse phenolic compounds [37] with beneficial properties for the health of ruminants. In particular, its anthelmintic properties were attributed to phenolic compounds [38]. The impact of tannins for human and animal health and nutrition was explained in detail $[36,39]$.

Meanwhile the accepted wide range of beneficial effects of phenolic compounds initiated attempts to stimulate their accumulation in crop plants by agricultural technologies. Several reviews present and discuss the modification of phenolic profiles in plants for possible nutritional enhancement of our diet [40,41]. Schreiner and Huyskens-Keil [42] summarized the chances of targeted postharvest elicitor treatments to obtain fruits and vegetables enriched with health beneficial phytochemicals. The significance of anthocyanins in human diet and the occurrence in foods as well as selected agronomic influences were reviewed by de Pascual-Teresa and Sanchez-Ballesta [43]. An overview on agricultural practices for enhanced human health was given by Martínez-Ballesta et al. [44]. Ruiz-Rodriguez et al. [45] and Amarowicz et al. [46] summarized the influence of postharvest processing and storage on the content of phenolic compounds in foods.

Besides the nowadays desired enhancement of phenolic compounds in plant crops, in the past, several undesired phenolic compounds were removed by breeding and selection of varieties with a weak biosynthesis of secondary metabolites [47]. Critical in this regard are the furanocoumarins which act as phytoalexins and may induce contact dermatitis in sensitive people. The presence and levels of these compounds can be influenced by several plant treatments and storage conditions [48-50].

Concurrently with the increasing popularity with respect to nutrition and human health the interest in phenolic compounds has also increased among plant scientists. Within the last four decades the opinion that phenolic metabolites are of major ecological and physiological importance has spread. The arguments against the old waste-product lobby were listed by [47] and [51]. Phenolic compounds contribute significantly to plant resistance against pests, pathogens and environmental stress [52]. They act as multifunctional metabolites in plants (Figure 1) being effective as sun screens, interacting with many enzymes and with growth regulators. They also may function as antioxidants in plants, a 
property which, however, is still a matter of debate [53]. Since information on insoluble phenolics bound to polymeric matrices is scarcely available, only data on the soluble pools being extractable with aqueous - organic solvents are considered here, taking into account that insoluble components may be released in the intestinal tract $[54,55]$.

Figure 1. Multifunctionality of phenolic compounds.

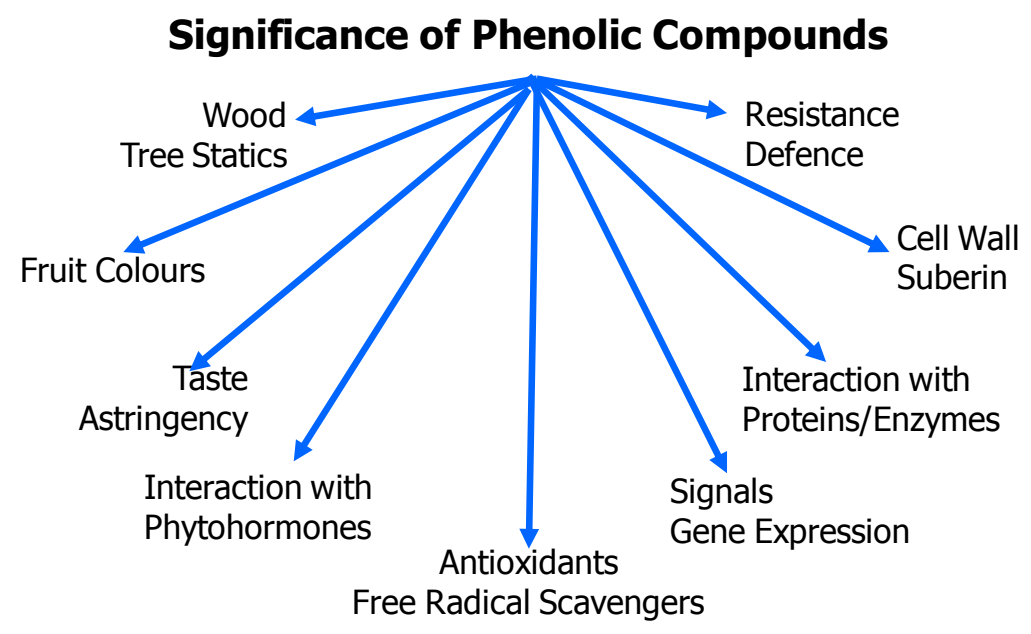

The aim of this article is to review visions and efforts being undertaken to manage the content and the profile of phenolic compounds in crop plants by cultivation technology, by using the genetic diversity of natural resources and by breeding. The outcome of those efforts is discussed with respect to their relevance on the basis of examples selected from literature. It is attempted to elucidate possible mechanisms behind the plant's response to cultivation technologies. Further questions are treated: are there constraints, unexpected feed-back loops and physiological side effects? Which way shall we go in agricultural quality production?

\section{Structures and Biosynthesis}

Natural phenols in plants are derived from the shikimate pathway from which the gallic acid molecule and its polymeric gallotannins and ellagitannins are directly derived. As a further product from that pathway the amino acid phenylalanine is released. This amino acid is the precursor of phenylpropanoids and further phenolic classes derived from them. These are flavonoids, isoflavones, pterocarpans, stilbenes, coumarins, phenolamines, aurones, chalcones, lignans and lignin. A simplified example of flavonoid biosynthesis is given in Figure 2. For further details on biosynthesis and structures the reader is referred to [56-61]. 
Figure 2. Simplified scheme of the biosynthesis of selected phenolic compounds. Abbreviations: ANR: anthocyanidin reductase, ANS: anthocyanidin synthase, $\mathrm{C} 4 \mathrm{H}$ : cinnamate 4-hydroxylase, CHI: chalcone isomerase, CHS: chalcone synthase, 4CL: p-coumarate:CoA ligase, Coum3H: coumaroyl 3-hydroxylase, DFR: dihydroflavonol 4-reductase, F 3'-H: flavonoiod 3'-hydroxylase, FGT: flavonoid glycosyltransferase, FHT: flavanone 3-hydroxylase, FLS: flavonol synthase, FNS: flavone synthase, IFS: isoflavone synthase, LAR: leucoanthocyanidin reductase PAL, phenylalanine ammonia lyase.

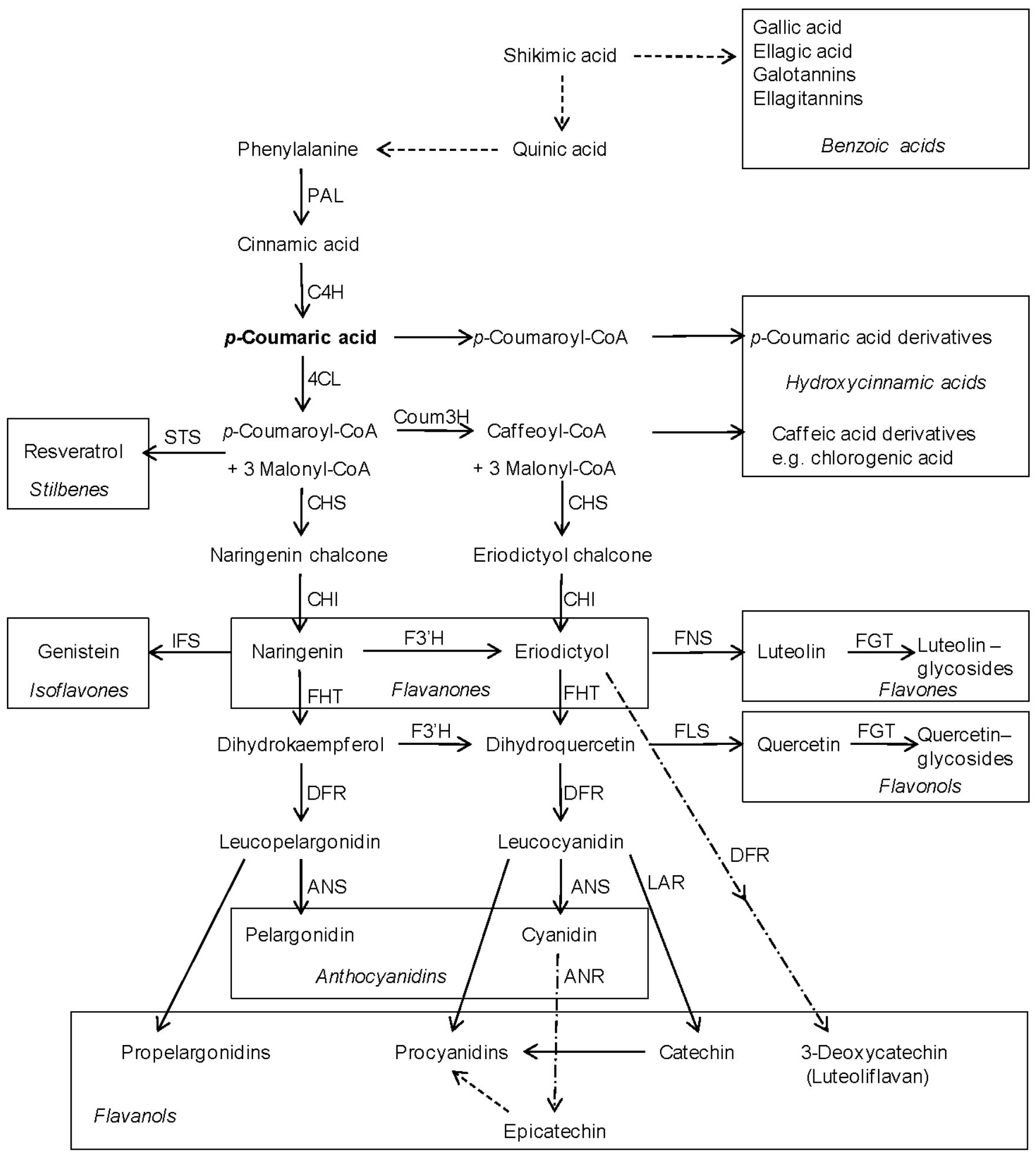




\section{Environmental, Nutritional, Agronomic and Developmental Clues Affecting Phenol Content in Crop Plants}

\subsection{Light Effects}

It is well known that the secondary metabolism of plants is markedly influenced by changing environmental conditions. On the other hand phenolic profiles can be used for cultivar identification, which was applied for roses [62], geranium [63], gerbera [64], azalea [65], sweet cherries [66,67,68], sour cherries [69], pelargonium [70] and plums [71]. The phenolic profiles of plants of a given variety propagated under different environments can be adapted when transplanted to the same location and grown there for a few weeks. Thereafter, the new sprouts and the newly formed leaves of the same variety formerly propagated at different locations showed identical phenolic profiles [70] and cultivars could be differentiated. A study on grape varieties in Greece [72] could differentiate wines based on cultivar and geographical origin with application of chemometrics of their principal polyphenolic constituents. However, [73] stated that winemaking style and technology seem to be more decisive for the polyphenolic composition of red wines than other factors.

The examples described above show the interest in stable phenolic fingerprints for variety discrimination. On the other hand, plant growers take advantage of environmental effects on crop yield and quality and, moreover, agricultural technologies have been developed to optimize Nature's control. A prominent example is the management of the skin color of apple fruits which is equivalent of controlling anthocyanin biosynthesis and accumulation. The red skin of apple fruits is due to accumulation of anthocyanins and for weakly colored cultivars it is a suitable marker for both fruit development and inner fruit quality. Only those fruits developing on young, vigorous spurs and being exposed to sunlight exhibit strong sink potential for attraction of substantial amounts of assimilates from the leaves. A high sugar content of the fruits is an important parameter of fruit quality and is a prerequisite for the formation of flavor as well. Many apple cultivars produce anthocyanins as red pigments when exposed to sun light thus the red skin correlates with fruit quality as expected by the consumer (Figure 3)

Figure 3. Relationship between red coloration of apple skin and taste evaluation (data from [74]).

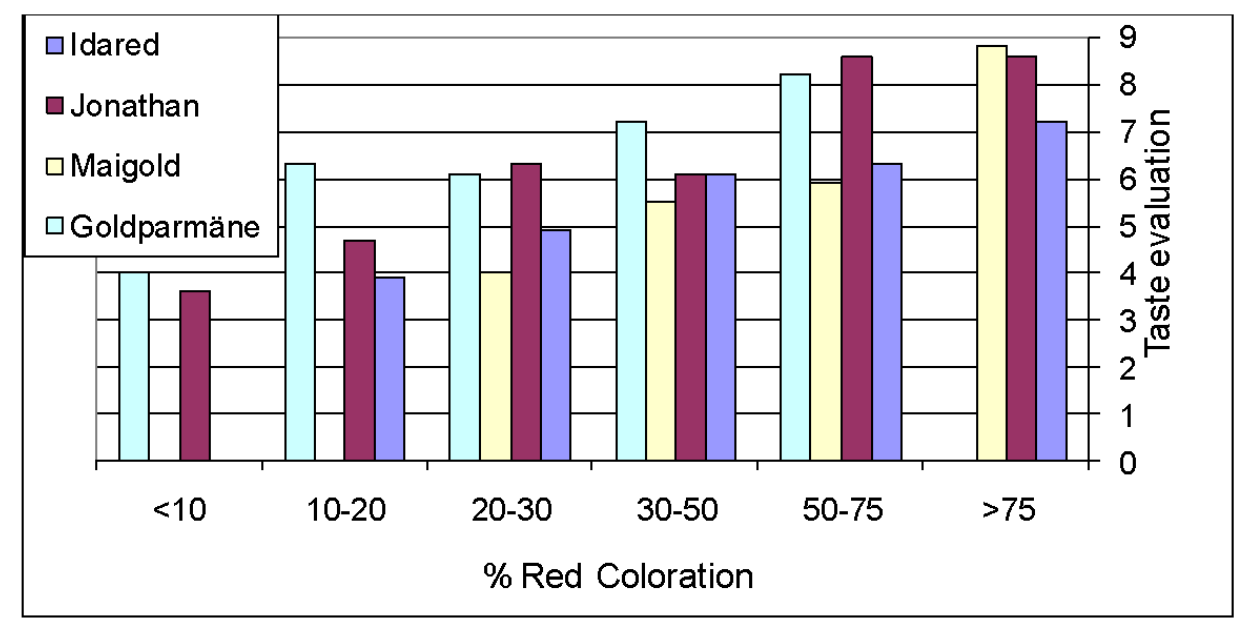


Improved pigmentation of 'Fuji' apples was obtained by covering the orchard floor with light reflecting films [75]. The red pigmented fruit area increased from 11 to $38 \%$ corresponding to an increase in anthocyanin concentrations in the peel from 0.18 to $0.37 \mathrm{mg} / \mathrm{g}$ fresh weight. As a key enzyme for the accumulation of anthocyanins the activity of UDPGalactose:flavonoid-3-Oglucosyltransferase (UFGalT) was measured. The improved light conditions enhanced the enzyme activity from about 7 to 10 pkatal/mg protein. Other flavonoids were not influenced in that study [75]. The position of apple fruits on the tree is a main factor of light perception. Besides the accumulation of anthocyanins, the concentration of flavonols in apple skin also depends on the position in the tree [76] and reflects the percentage of red coloration and the sun exposure of the fruits. In contrast to the behavior of these flavonoids the concentrations of the dihydrochalcone phloridzin, of the catechins and of chlorogenic acid remained unaffected (Table 1). The accumulation of flavonols in apple skin when exposed to sunlight has been confirmed [77,78].

Table 1. Red coloration of apple fruits and content of phenolic compounds (mg/g dry weight) in the skin as affected by fruit position in the tree. Data from [75].

\begin{tabular}{|c|c|c|c|c|c|c|}
\hline $\begin{array}{c}\text { Position } \\
\text { on tree }\end{array}$ & $\begin{array}{c}\text { \% Red } \\
\text { coloration }\end{array}$ & $\begin{array}{c}\text { Cyanidin - } \\
\text { galactoside }\end{array}$ & $\begin{array}{c}\text { Quercetin } \\
\text { glycosides }\end{array}$ & Catechins & Phloridzin & $\begin{array}{c}\text { Clorogeni } \\
\text { c acid }\end{array}$ \\
\hline Top & 38.0 & 0.6 & 8.8 & 3.0 & 1.2 & 0.17 \\
Outer west & 20.5 & 0.3 & 6.8 & 3.5 & 1.2 & 0.21 \\
Outer east & 14.2 & 0.2 & 7.0 & 3.7 & 1.2 & 0.20 \\
Inner & 0.0 & 0.0 & 2.5 & 3.6 & 1.1 & 0.20 \\
\hline
\end{tabular}

Beside a strong increase in anthocyanins and quercetin-glycosides as a result of sun-exposure, Hagen et al. [79] also found an about doubling of the values for epicatechin, procyanidins, phloridzin and an enhancement of chlorogenic acid in the peel of the apple cultivar 'Aroma'. A postharvest irradiation treatment furthermore increased the total flavonoid concentrations but the individual compounds responded differently [79]. The impact of light exposure on the phenolic content and composition is reported in several other plants. Outer and inner leaves of lettuce heads differ in their concentrations of flavonoids [80]. Whereas outer leaves of the cultivars 'Newton' and 'Rosalie' exhibited concentrations of quercetin of 1.2 and $0.9 \mathrm{mg} / \mathrm{g}$ dry weight and luteolin of 0.11 and $0.16 \mathrm{mg} / \mathrm{g}$ dry weight, their inner counterparts accumulated only 3 to $7 \%$ of those values. When the inner leaves were opened and illuminated, an increase of the flavonoid levels up to the concentrations of the outer leaves took place. This coincides with an increase of chlorophyll and, probably, photosynthetic activity [80]. A short high light exposure $\left(800 \mu \mathrm{mol} / \mathrm{m}^{2} \mathrm{~s}\right)$ for 1 day of young lettuce plants and analysis 3 days later revealed a pronounced increase of chlorogenic acid, chicoric acid, quercetin 3-O-glucoside and luteolin 7-O-glucoside [81].

The level of condensed tannins measured as tannin containing cells increased by increasing light intensity in leaves of Lotus corniculatus [82]. Soybean sprouts which are usually grown under dark conditions produce fewer amounts of isoflavones $(0.56 \mathrm{mg} / \mathrm{g}$ fresh weight) as compared to green sprouts grown under light $(1.38 \mathrm{mg} / \mathrm{g}$ fresh weight) [83]. Pruning and training of fruit trees and grape vines are commonly used practices to improve light perception of fruits and to increase red pigmentation. Fruit cluster thinning in grape skins cv. Syrah (Vitis vinifera) reduced the yield from 8 to 
4 tons per hectare but nearly doubled the final concentration of the anthocyanin malvidin 3-glucoside in the fruits while flavonols remained unaffected [84]. Strawberry fruits do not seem to respond in such a strong way to light or shading [85]. No significant light effects on anthocyanin formation were found in ripening red raspberry fruits [86].

The effects of light on the accumulation of phenolic compounds in plant tissues may not only be explained by providing energy for carbon assimilation thus providing carbon resources for biosynthesis. It is furthermore the quality, namely the UV fractions, which stimulate the formation and accumulation of certain phenolic compounds in plants. Light and particularly UV-light enhances anthocyanin biosynthesis in apple fruit skins [87,88]. A further example is the cultivation of lettuce cv. 'Lollo Rosso' under plastic films with ultraviolet transparency [89]. When the concentration of anthocyanins in the leaves $(\mu \mathrm{g} / \mathrm{g}$ fresh weight) were compared to plants grown under plastic film which blocks UV radiation, thus resembling a glass house, levels of the red pigments were more than doubled (Table 2). However, UV light also causes growth reduction by one third of the fresh weight and number of leaves was diminished by about $10 \%$.

Table 2. Growth parameters and anthocyanin concentrations in green and red leaves of lettuce cv. 'Lollo Rosso' grown under plastic films with and without UV transparency. Data from [89].

\begin{tabular}{|c|c|c|c|c|}
\hline $\begin{array}{l}\text { UV transparency } \\
\text { of the polytunnel }\end{array}$ & $\begin{array}{l}\text { Fresh weight } \\
\text { of the lettuce }\end{array}$ & $\begin{array}{c}\text { Leaf } \\
\text { number }\end{array}$ & Plant sample & $\begin{array}{c}\text { Anthocyanins } \\
\text { ( } \mu \mathrm{g} / \mathrm{g} \text { fresh weight) }\end{array}$ \\
\hline no & 320 & 27 & green leaves & 25 \\
\hline no & & & red leaves & 375 \\
\hline yes & 190 & 23 & green leaves & 75 \\
\hline yes & & & red leaves & 992 \\
\hline
\end{tabular}

In another experiment [90], the UV-filter effect of a polycarbonate green house was assumed as the main reason for low levels of hydroxycinnamic acids and flavonoids in outer leaves of lettuce cv. Audran. In Table 3 the concentrations of phenolic compounds of these leaves 16 days after planting are compared with those from leaves grown outdoor. The general environmental conditions differed as follows: In the greenhouse, maximum photon photosynthetic flow (PPF) was $800 \mathrm{mE} \mathrm{m}^{-2} \mathrm{~s}^{-1}$ with the temperature between 15 and $29^{\circ} \mathrm{C}$; in the open air the maximum PPF was of $1,100 \mathrm{mE} \mathrm{m} \mathrm{m} \mathrm{s}^{-1}$ with temperature between 10 and $20^{\circ} \mathrm{C}$.

Table 3. Phenolic compounds ( $\mathrm{mg} / \mathrm{g}$ fresh weight) in outer leaves of lettuce grown in open air and in a polycarbonate greenhouse, 16 days after planting [90].

\begin{tabular}{|l|c|c|}
\cline { 2 - 3 } \multicolumn{1}{c|}{} & open air & greenhouse \\
\hline Chlorogenic acid & 0.77 & 0.41 \\
Chicoric acid & 1.17 & 0.48 \\
Quercetin glycosides & 0.30 & 0.01 \\
\hline
\end{tabular}

UVB irradiation of Betula sp. seedlings for two months increased the concentrations of quercetin glycosides in the leaves [91]. When grapevine plants grown in the greenhouse were placed outside and 
exposed to UV-B light, the berries' response was an accumulation of flavonols but not of hydroxycinnamic acids which results in a lack of UV-B screen whereas UV-A shielding by flavonols was improved [92]. Petunia plants exposed to UV-B showed a stimulated biosynthesis of flavonols with an increased quercetin/kaempferol ratio [93].

\subsection{Temperature}

Apples grown in warm climates often lack of sufficient skin coloration. This may mostly be due to high night temperatures during the last weeks prior to harvest. It was found that low night temperature during fruit ripening is a trigger for accumulation of red pigments in apple fruit skins [94] (Figure 4). Since consumers and retailers ask for red pigmented apple fruits the grower is enforced to postpone harvest under warm weather conditions. This may cause some disadvantages with respect to the storability of the fruits since other ripening related processes such as cell wall and starch degradation may have been accelerated before anthocyanin biosynthesis had started.

Figure 4. Development of red pigmentation of apple fruits cv. 'Red Chief' (\% coloration) ripening under warm day $\left(26^{\circ} \mathrm{C}\right)$ and warm night $\left(22^{\circ} \mathrm{C}\right)$ conditions $(\mathrm{A})$ and under warm day $\left(26^{\circ} \mathrm{C}\right)$ and cool night $\left(11^{\circ} \mathrm{C}\right)$ conditions (B). Data from [94].

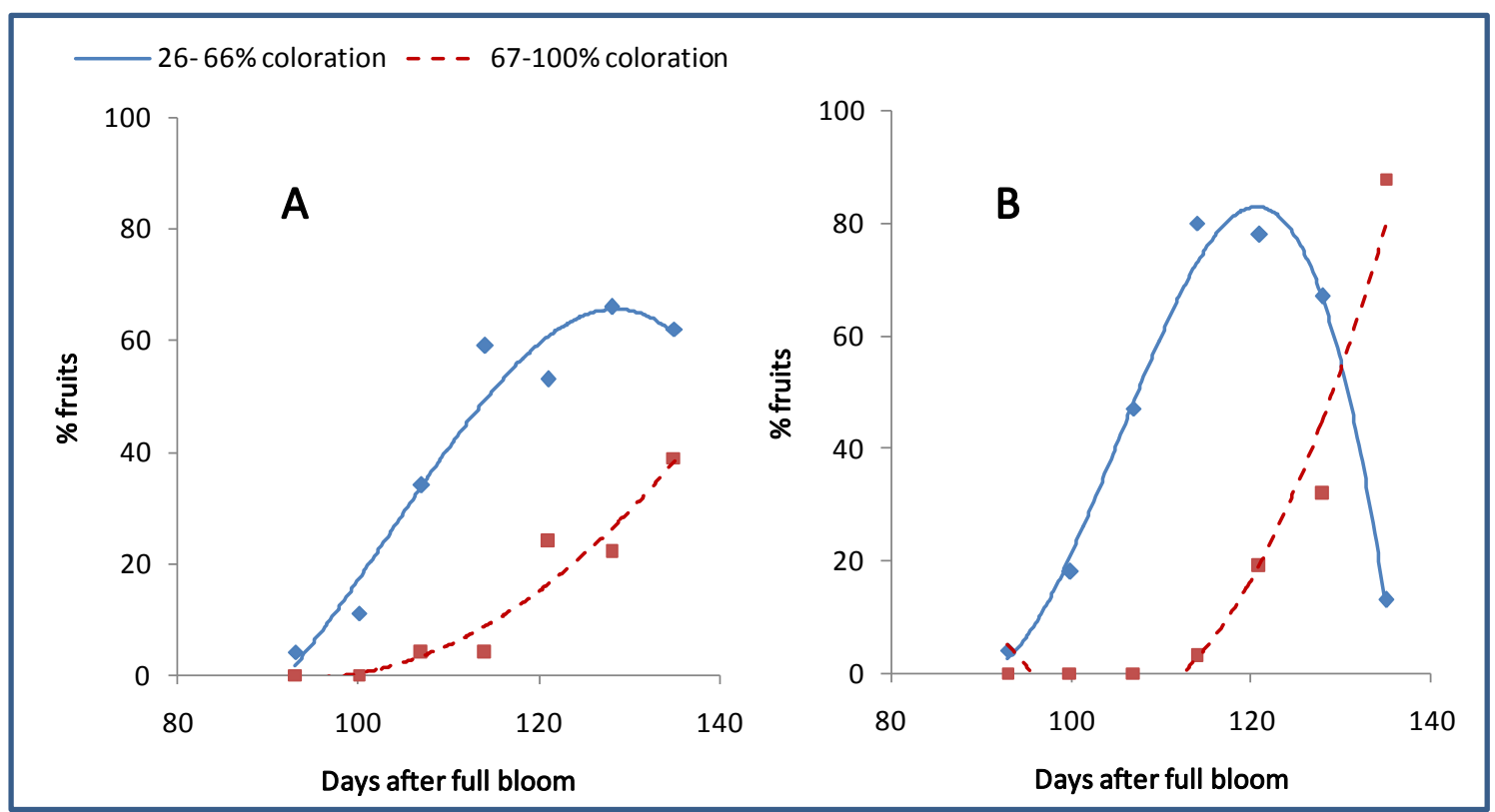

Low night temperatures also favour anthocyanin accumulation in grape berries [95]. At veraison plants were placed in a phytotron and grown under two day/ night temperature regimes: $30{ }^{\circ} \mathrm{C} / 30{ }^{\circ} \mathrm{C}$ and $30{ }^{\circ} \mathrm{C} / 15^{\circ} \mathrm{C}$. Under the low night temperature conditions the berry skin accumulated up to $5.5 \mathrm{mg}$ anthocyanins per $\mathrm{g}$ fresh weight whereas the concentration in the warm night variant was $4 \mathrm{mg} / \mathrm{g}$ fresh weight estimated at 45 days after veraison. Higher activity of PAL and in particular UFGT was found at low night temperatures coinciding with a high expression level of the UFGT gene [95]. In strawberries, high temperature during cultivation may generally promote the phenolic content of the fruits. This was shown for anthocyanins and p-coumaroyl glucose [96] (Table 4). 
Table 4. Effect of plant growth temperature (day/night ${ }^{\circ} \mathrm{C}$ ) on concentrations $(\mu \mathrm{g} / \mathrm{g})$ of phenolic compounds in fruit juice of strawberry cv. 'Kent'; data from [96].

\begin{tabular}{|l|c|c|c|c|}
\cline { 2 - 5 } \multicolumn{1}{c|}{} & \multicolumn{4}{c|}{ Temperature (day/night, ${ }^{\circ}$ C) } \\
\hline Phenolic compound & $18 / 22$ & $25 / 12$ & $25 / 22$ & $30 / 22$ \\
Pelargonidin glycosides & 449.1 & 623.1 & 880.5 & 1220.5 \\
Cyanidin glycosides & 36.5 & 42.4 & 45.3 & 65.6 \\
p-Coumaroyl glucose & 30.8 & 46.7 & 61.5 & 73.4 \\
Quercetin glycosides & 2.2 & 3.6 & 15.7 & 21.4 \\
Kaempferol glycosides & 2.4 & 3.4 & 4 & 6.2 \\
\hline
\end{tabular}

A short time stress treatment applying heat shock $\left(40{ }^{\circ} \mathrm{C}\right.$ for $\left.10 \mathrm{~min}\right)$ or chilling $\left(4{ }^{\circ} \mathrm{C}\right.$ for 1 day) to young lettuce plants induced the accumulation of chlorogenic acid and chicoric acid while quercetin 3-O-glucoside and luteolin 7-O-glucoside only increased as a response to cold temperature [97]. In this context it has to be mentioned that red orange fruits (Citrus sinensis) accumulated anthocyanins in their juice vesicles during cold storage at $4{ }^{\circ} \mathrm{C}$ for a period of 75 days. This was measured as a linear increase starting from day 30 with a concentration of $1.5 \mathrm{mg} / 100 \mathrm{~g}$ fresh weight and reaching nearly $8 \mathrm{mg} / 100 \mathrm{~g}$ fresh weight at day 75 [98]. At the same time the transcripts of PAL, CHS, DFR and UFGT increased manifold. An accumulation of phenolic compounds was also found in apple during cold storage which was coupled with increasing PAL activity [99].

\subsection{Mineral Nutrition}

Maintenance of minerals is a prerequisite for providing co-factors for many enzymes of the phenylpropanoid and flavonoid pathway. $\mathrm{Mg}^{2+}$ and $\mathrm{Mn}^{2+}$ ions ensure the functioning of PAL, of CoA-ligases, and of methyltransferases [100-103]. $\mathrm{Ca}^{2+}$-deficiency induced anthocyanin accumulation in cabbage [104] and could promote lignification [105]. The metabolism of Prunus callus tissues in vivo was affected by $\mathrm{Ca}^{2+}$ deficiency and responded with an accumulation of phenolic stress metabolites [106]. Deficiency of phosphate in several plants leads to red coloration of the leaves which means accumulation of anthocyanins. In Helianthus annuus an accumulation of chlorogenic acid was observed [107] and in tomato fruits an additional enrichment of flavanones [108]. Boron deficient plants are also known to accumulate phenolic compounds which may be related to an activated pentose phosphate pathway in that situation [109]. In an in vitro system using grapevine callus, an increase in boron concentration in the nutrient medium from 0 to $600 \mu \mathrm{M}$ was followed by a decline of catechins and proanthocyanidins by about $30 \%$ [110]. When $\mathrm{AlCl}_{3}$ was added to the medium in the same system of grapevine callus, an increase of the flavanols mentioned above by about $25 \%$ was measured. This may be attributed to a stress-type promotion as a response to aluminium [110].

The accumulation of phenolic compounds in plant tissues is often negatively affected by high $\mathrm{N}$-nutrition. This was described for barley [111], for apricot fruits [112] and, recently, for tobacco [113]. It was also shown for red pine [114], and for Pinus elliotti [115]. N fertilisation reduced the concentration of individual phenolics in leaves of Vaccinium myrtillus [116]. Similarly, an increase of flavonols in tomatoes and Arabidopsis thaliana was confirmed by [117]. The fact of decreasing contents of phenolic compounds in leaves and needles of plants grown under high $\mathrm{N}$ supply was also described for several other species including Abies grandis [118], Pinus sylvestris [119], Fagus 
sylvatica [120], Salix myrsinifolia [121] Betula pendula [122] and Betula pubescens [123-126]. When grown at high level of $\mathrm{N}$ supply, leaves of potato plants contained significant lower amounts of chlorogenic acid and flavonols as compared to plants without additional $\mathrm{N}$ fertilization [127]. Among the factors influencing the red pigmentation of apple excessive nitrogen fertilization is commonly known as an inhibitory treatment. In an experiment on 'Elstar Elshof' apples [128] found a reduction of the main pigment cyanidin 3-galactoside by more than $40 \%$ after excessive N-fertilization (Table 5). Flavonols, catechins and phloridzin were affected showing a reduction by less than $20 \%$ whilst chlorogenic acid remained unchanged.

Table 5. Effect of $\mathrm{N}$-fertilization on $\mathrm{N}$-content and on the content of phenolic compounds in apple skin (cv 'Elstar' mutant 'Elshof'). Data from [128].

\begin{tabular}{|l|l|l|l|}
\hline Fertilization level & $\mathbf{0}$ & $\mathbf{2}$ & $\mathbf{4}$ \\
\hline $\begin{array}{l}\text { N concentration in the fruits } \\
\text { (mg/100g fresh weight) }\end{array}$ & 32.0 & 41.1 & 54.1 \\
\hline \multicolumn{4}{|l|}{ Phenolic compounds in the skin (mg/g dry weight) } \\
\hline Cyanidin 3-galactoside & 1.1 & 0.86 & 0.64 \\
Quercetin glycosides & 4.9 & 4.8 & 4.3 \\
Catechins & 3.0 & 2.9 & 2.5 \\
Phoridzin & 0.86 & 0.95 & 0.75 \\
Chlorogenic acid & 0.047 & 0.053 & 0.045 \\
\hline
\end{tabular}

The effect of long-term N-supply on growth and phenolic compounds in the leaves of apple trees were examined in relationship to scab resistance [129]. The studies revealed a reduced accumulation of diverse phenol compounds except the hydroxycinnamic acids after fertilization with growth promoting amounts of nitrogen [129] (Table 6). The decrease of the phenolic concentrations by high $\mathrm{N}$-fertilization was accompanied by a pronounced increase of susceptibility of the leaves to apple scab.

Table 6. Phenolic compounds (mg/g dry weight) in young leaves of apple cv. 'Golden Delicious' as influenced by nitrogen fertilization with $\mathrm{N} 1$ as the conventional control and $\mathrm{N} 3$ as an excessive treatment. The $\mathrm{C} / \mathrm{N}$-ratios of the shoots indicate the different physiological situations. Data from [129].

\begin{tabular}{|l|r|r|}
\cline { 2 - 3 } \multicolumn{1}{c|}{} & \multicolumn{1}{c|}{ N1 } & \multicolumn{1}{c|}{ N3 } \\
\hline Shoots C/N ratio & 55.0 & 43.0 \\
Phloridzin (mg/g dw) & 78.0 & 50.0 \\
Flavonols (mg/g dw) & 11.5 & 9.0 \\
Phloretin (mg/g dw) & 7.0 & 2.0 \\
Hydroxycinnamic acids (mg/g dw) & 1.5 & 1.5 \\
Procyanidins (mg/g dw) & 1.4 & 1.0 \\
Catechins (mg/g dw) & 0.6 & 0.3 \\
\hline
\end{tabular}

Whereas the phenolic levels in apple fruits and leaves suffer from excessive N-fertilization, strawberries seem to accumulate highest phenolic amounts when they were grown under conditions optimized for plant growth and fruit yield $[130,131]$. Such conditions comprise the use of a compost 
substrate and full strength fertilizer (NPK, 20/20/20) applied twice a week. All phenolic classes studied namely the anthocyanins, flavonols, hydroxycinamic acids and ellagic acid, responded in the same way (Table 7).

Table 7. Phenolic compounds in fruit of strawberry cv 'Honeoye' as affected by fertilizer strength. Data from [131].

\begin{tabular}{|l|r|r|r|}
\hline Phenolic compounds & \multicolumn{3}{|c|}{ Fertilizer } \\
\hline$\mu \mathrm{g} / \mathrm{g}$ fresh weight & \multicolumn{1}{|c|}{ none } & half strength & full strength \\
\hline Pelargonidin glycosides & 807.0 & 855.1 & 923.5 \\
Cyanidin glycosides & 18.4 & 24.3 & 37.9 \\
p-Coumaroyl glucose & 47.0 & 49.3 & 70.5 \\
Kaempferol glycosides & 12.1 & 13.8 & 15.1 \\
Ellagic acid & 2.2 & 3.9 & 6.3 \\
\hline
\end{tabular}

Conflicting results are presented by Anttonen et al. [132] who showed reduced phenolic concentrations in strawberry fruits by increasing nitrogen fertilization. However, from that experiment no information is available with respect to plant growth and yield. In Solanum carolinense an increase of phenolics was observed with increasing $\mathrm{N}$-amendment [133]. Increased $\mathrm{N}$ nutrition of young birch seedlings reduced the level of soluble condensed tannins but increased its insoluble pool [91]. It is suggested that an increase in $\mathrm{N}$, from deficiency to moderate, may enhance the accumulation of condensed tannins in the cell wall. A reduction of tannins in barley as a consequence of high $\mathrm{N}$ fertilization was reported by Sørensen et al. [134]. A more differentiated effect was found when wheat (Triticum aestivum) was extensively fertilized with nitrogen [135]: soluble phenolic acids increased in the straw but they were reduced in the corn. In the corn, additionally, a metabolic shift from p-coumaric acid towards ferulic acid occurred.

In cell cultures of grapevine and maple the quantity of anthocyanins was reduced when cultivated on high $\mathrm{N}$ containing medium [135,137]. In an experiment with apple skin discs anthocyanin formation coud be reduced by floating the tissue with urea while protein synthesis increased [138]. This was interpreted as an antagonistic relationship between anthocyanin development and protein synthesis. In leaves of Hedera helix turning red in the fall season both protein and anthocyanin biosynthesis occurred [139]. This is suggested to be possible because of the high sugar to protein ratio. Margna [140] provided evidence that phenylalanine may be the rate-limiting factor for phenylpropanoid biosynthesis. However, protein degradation can be regarded as an alternative source for phenylalanine [141,142] (Figure 5). Recently, a downregulation of genes encoding for enzymes involved in the phenylpropanoid metabolism by nitrate as a proposed signal was described for Arabidopsis and tobacco [143,144].

Bongue-Bartelsman and Phillips [145] showed in case of nitrogen deficiency a modification of gene expression, which was not uniform. While the steady-state mRNA-levels of CHS and DFR in Lycopersicon esculentum increased under $\mathrm{N}$ deficiency stress, the steady-state levels of a CHI homologues band decreased at the same time. In the same plants also an accumulation of quercetin-3$O$-glucoside and petunidin was found. A differentiated effect of nitrogen depletion on gene expression and product formation in different branches of the flavonoid pathway was described for Arabidopsis 
[146]. Decreasing activities of PAL were described in apple trees grown under high $\mathrm{N}$ and K supply [147]. Strissel et al. [148] confirmed this observation for high $\mathrm{N}$ supply in apple showing an impact on enzyme activity and on the content of metabolites.

Figure 5. Different L-phenylalanine pools for the biosynthesis of phenolic compounds [141,142].

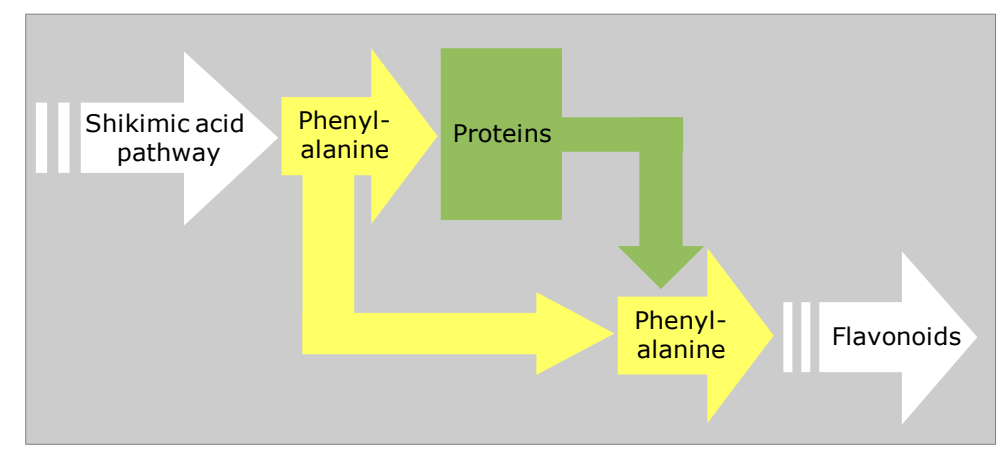

\subsection{Water Management and Irrigation}

Plants grown under stress conditions often produce and accumulate phenolic stress metabolites [149-151]. Water deficiency is supposed to stimulate synthesis of phenolic stress metabolites in tomato. However, it was found that the concentration of flavonols on a fresh weight basis only reflected the reduced water content [152]. A similar effect was described for grape berries [153]. However, in years with water deficiency the flavonoid profile was shifted towards flavonols at the expense of flavanols [154]. A two years experiment with grape vine cv. 'Tempranillo' revealed that the highest amount of anthocyanins was produced under optimum water supply [155]. In a nonirrigated plot with pronounced yield reduction and reduced berry weight exceptionally only in one year a higher anthocyanin concentration was found when calculated on a fresh weight basis. When estimating the amount per berry, irrigation increased the accumulation of anthocyanins by more than $25 \%$ as compared to the non-irrigated variant. It may be concluded from these observations that with respect to water supply optimized cultivation technology favoring plant growth and fruit yield also assists the formation of anthocyanins. In a water logging experiment causing a growth retarding stress situation for cherry trees, [156] observed an increase of diverse phenolic compounds in the leaves.

\subsection{Effect of Rootstocks}

The propagation of many fruit tree varieties is only successful by grafting on compatible rootstocks. During centuries of fruit growing, rootstock genotypes have been selected which influence growth vigor of the combined tree consisting of two genetically different partners. Special scion/rootstockcombinations have been developed for optimized fertility, fruit yield and for high fruit quality which benefit from the rootstock's influence on uptake and transport of water and minerals [157]. The interaction between the two partners also changes the hormonal situation in both the scion and the rootstock [158-160]. The effect of grafting on the phenolic compounds in the bark just above the union was studied for cherries and apricots with an accumulation of $p$-coumaroylglucose, of flavanones (i.e., naringenin 7-glucoside), of the isoflavone genistin and of flavan 3-ols in 
cherries [161-163] and of flavan 3-ols in apricot [164]. The accumulation of those metabolites may indicate a lack of differentiation in the phloem and cambium region of the bark $[165,166]$ since naringenin 7-glucoside and high concentrations of flavan 3-ols are potent markers of undifferentiated callus-like cells [167]. The altered phenolic profiles in the leaves of particular stressed Prunus avium/P. cerasus graft combinations which are characterized by an accumulation of chlorogenic acid, catechin and quercetin glycosides [168] may indicate an overall rootstock effect on the whole tree system. Recent studies on lemon trees revealed a pronounced accumulation of di- $C$-glucosyl diosmetin due to the use of sour orange rootstock instead of Citrus macrophylla [169]. The concentration increased from about 500 to more than $1,000 \mathrm{mg} / \mathrm{L}$ juice.

\subsection{Elevated Atmospheric $\mathrm{CO}_{2}$}

Global climatic change comes along with an increase of $\mathrm{CO}_{2}$ levels in the atmosphere. The increased supply of carbon may favor plant growth and provide resources for carbon based secondary metabolites. It was shown for tobacco that under limited nitrogen supply the ratio of secondary metabolites changed in favor of carbon-based phenolic compounds at the expense of alkaloids [113] when grown under elevated $\mathrm{CO}_{2}$ concentrations. Grapevine grown under elevated $\mathrm{CO}_{2}$ concentrations in a "Free-Air $\mathrm{CO}_{2}$-Enrichment" experiment produced more biomass and fruit yield increased. The general quality of the wine was not affected but the concentrations of anthocyanins and other flavonoids tended to increase [170]. High anthocyanin and phenolic content were also found in strawberry fruits [171] when plants were grown under $\mathrm{CO}_{2}$ enrichment conditions (ambient $+600 \mu \mathrm{mol} / \mathrm{mol}$ ). Fruit $p$-coumaroylglucose increased from 417 to $735 \mu \mathrm{g} / \mathrm{g}$ dry weight, quercetin glycosides from 27 to $108 \mu \mathrm{g} / \mathrm{g}$ dry weight, kaempferol glycosides from 108 to $138 \mu \mathrm{g} / \mathrm{g}$ dry weight, cyanidin 3-glucoside from 561 to $1,153 \mu \mathrm{g} / \mathrm{g}$ dry weight, pelargonidin 3-glucoside from 2,124 to $3,669 \mu \mathrm{g} / \mathrm{g}$ dry weight. Elevated atmospheric $\mathrm{CO}_{2}$ under non-limiting nutrient and water supply increased condensed tannins and flavonol glycosides in birch seedlings [172] and total phenolics in Pinus eliotti [173]. The same trend was found in perennial grasses [174] and in Plantago maritima [175] as well as in several tropical trees [176]. In Ligustrum vulgare Tattini et al. [177] showed an accumulation of hydroxycinnamic acids and flavones as the $\mathrm{CO}_{2}$ assimilation increased. Elevated $\mathrm{CO}_{2}$ increased the concentration of the phenolic acids (125\%), myricetin glycosides (118\%), catechin derivatives $(113 \%)$ and soluble condensed tannins (119\%) by increasing their accumulation in the leaves of the silver birch trees, but decreased the flavone aglycones by growth dilution [178]. The altered flavonoid profiles under elevated $\mathrm{CO}_{2}$ may indicate that the physiological ageing of the respective trees was accelerated. Other experiments, however, failed to show an effect of elevated $\mathrm{CO}_{2}$ on phenolic compounds [179].

\subsection{Differentiation and Development}

During tissue differentiation and organ development the phenolic profiles often undergo remarkable changes indicating that their metabolism is integrated into programs of growth and development. In the skin of young apple fruits cv 'Golden Delicious' at beginning of June the concentration of chlorogenic acid exhibits values of up to $30 \mu \mathrm{M} / \mathrm{g}$ dry weight dropping sharply down to $2 \mu \mathrm{M}$ up to July and further reaching values near zero in the skin of mature fruits in September. Flavonol glycosides and 
phloridzin also show high concentrations in the skin of young fruits in June but with a plateau up to July and dropping down to about $30 \%$ of the initial values with concentrations in the mature fruits of $10 \mu \mathrm{M} / \mathrm{g}$ dry weight for phloridzin and $21 \mu \mathrm{M} / \mathrm{g}$ dry weight for flavonol glycosides [180]. Within the class of flavan 3-ols, catechin showed a similar behavior as flavonols but between 4 and $0.1 \mu \mathrm{M} / \mathrm{g}$ dry weight. Epicatechin and its oligomeric procyanidins started with about 10 and $7 \mu \mathrm{M} / \mathrm{g}$ dry weight, respectively, in June increasing to a maximum of about 20 and $26 \mu \mathrm{M} / \mathrm{g}$ dry weight, respectively, in July and dropping down to the initial values up to September. In developing strawberry fruits two distinct activity peaks could be demonstrated during fruit ripening at early and late developmental stages for most enzymes of the flavonoid pathway with the exception of flavonol synthase. The first activity peak corresponds to the formation of flavanols (catechin and procyanidins), while the second peak is clearly related to the accumulation of anthocyanins (pelargonidin glycosides) and flavonols (quercetin glycosides) [181] (Figure 6).

Figure 6. Flavonoid biosynthesis in strawberry fruits indicating development related pathways restricted to young and mature fruits, respectively [181].

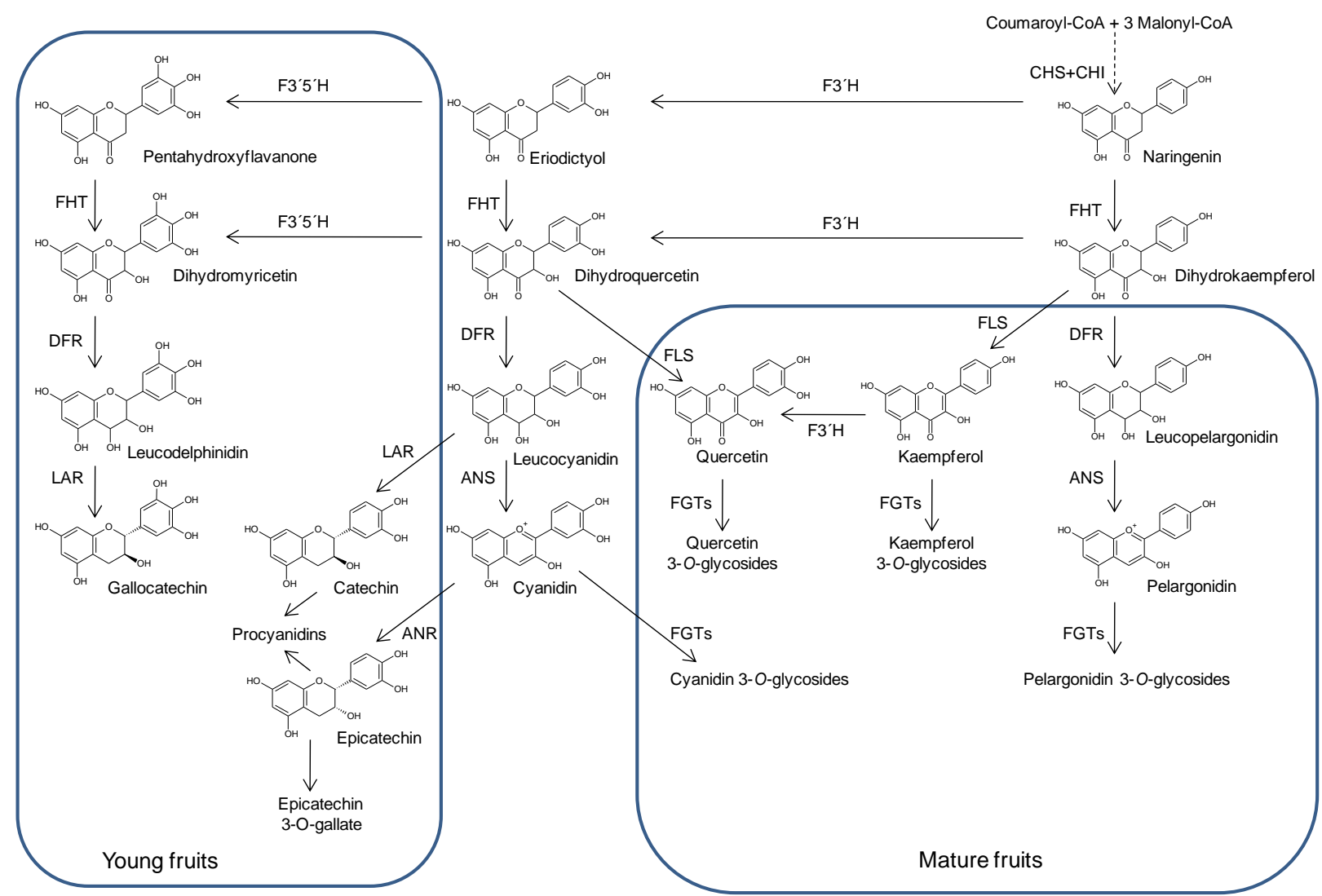

Note: F3'5' $\mathrm{H}$ = favonoid 3',5'-hydroxylase, FGTs = flavonoid glycosyl transferases, other abbreviations see Figure 2.

At the early stages of bilberry fruit development, procyanidins and quercetin were the major flavonoids, but the levels decreased dramatically during the progress of ripening. During the later stages of ripening, the content of anthocyanins strongly increased and they were the major flavonoids in the ripe berry [182]. Raspberry fruits also focus on anthocyanin formation during ripening [183]. Whereas ellagic acid showed high levels of nearly $300 \mu \mathrm{g} / \mathrm{g}$ fresh weight in unripe fruits its 
concentrations declined to $25 \%$ in fully ripe berries. Flavonols also decrease during ripening, for example quercetin 3-glucuronide from about $140 \mu \mathrm{g} / \mathrm{g}$ fresh weight to $25 \mu \mathrm{g} / \mathrm{g}$ fresh weight, while cyanidin-glycosides accumulate to more than $800 \mu \mathrm{g} / \mathrm{g}$ fresh weight with 60 and $83 \mu \mathrm{g} / \mathrm{g}$ fresh weight for cyanidin 3-sophoroside and cyanidin 3-rutinoside, respectively, and $380 \mu \mathrm{g} / \mathrm{g}$ fresh weight for cyanidin 3-glucoside and $320 \mu \mathrm{g} / \mathrm{g}$ fresh weight for cyanidin 3-glucosylrutinoside [183]. The inner bark of cherry shoots also showed developmental changes with respect to their flavonoid profiles [184]: In spring, the flavanone dihydrowogonin 7-glucoside reached concentrations of about $26 \mathrm{mg} / \mathrm{g}$ dry weight which fell down to $21 \mathrm{mg} / \mathrm{g}$ dry weight. During the same period, the isoflavone genistin increased from 1 to $4 \mathrm{mg} / \mathrm{g}$ dry weight.

When we attempt to actively influence phenolic profiles in plants we must keep in mind that biosynthesis and accumulation of phenolic compounds are mostly restricted to specialized cells and tissues and, moreover, at a subcellular level $[150,185]$. In close connection to their role as sun screens [186], the occurrence of flavonols in some plant organs is restricted to epidermal cells such as in grapevine leaves [187]. Infected cotton leaves were found to accumulate epidermal flavonoids (quercetin 3-O-glucoside, cyanidin 3-O-glucoside) in restricted areas where they are essential in protecting leaf tissue from light-dependent terpenoid phytoalexins [188].

The skin of apple fruits being exposed to the environment may function as a protective layer thus expressing biosynthetic pathways different to those of the flesh and the core. In 'Golden Delicious' the glycosides of the flavonol quercetin are mainly accumulated in the skin whereas their concentrations in the inner parts of the fruit are quite low [180] (Figure 7). Chlorogenic acid on the other hand shows highest concentrations in the flesh and the core. Epicatechin and its oligomeric procyanidins are more or less equally distributed among the tissues but the level in the core decreases dramatically in June. The levels of phloridzin and catechin are seasonally regulated with highest values in the very young tissues in May.

Figure 7. Tissue specific levels of phenolic compounds in young apple fruits cv. 'Golden Delicious' in May and June. Data from [180].
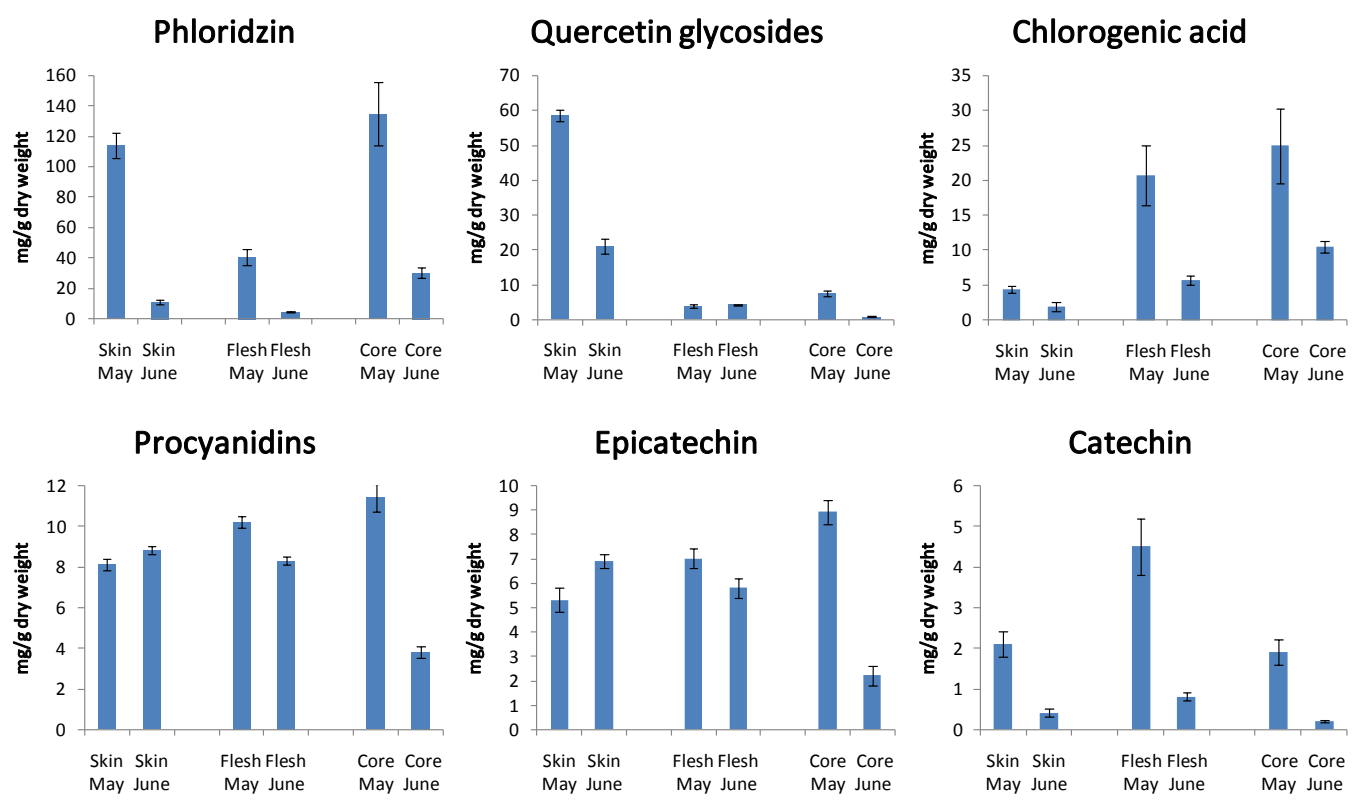


\subsection{Treatment of Plants with Elicitors, Stimulating Agents and Plant Activators}

Ethanol spray: A perspective to improve grape berry color of anthocyanin deficient varieties or of grapes cultivated in inappropriate climate areas was offered by using ethanol as a spray [189]. Spraying a 5\% ethanol solution on 'Cabernet Sauvignon' grapes at veraison (=time when berries turn from green to purple) increased anthocyanins up to 3-fold until harvest [189]. The improved accumulation was correlated with an induced expression of a glycosyltransferase gene UFGT (UDP glucose-flavonoid 3-O-glucosyltransferase). It is supposed that an unknown regulatory gene is active which is probably related to fruit ripening.

Spraying of nutrients and plant activators: Several reports describe the phenol enhancing effect of the nutrient solution 'Brotomax' which contains urea nitrogen, copper, manganese and zinc according to the manufacturer. After spraying it on olive trees [190], several phenolic compounds increased in the cortex of the stem: tyrosol from $4.2 \mathrm{mg} / 100 \mathrm{~g}$ fresh weight in the untreated cortex to $5.5 \mathrm{mg} / 100 \mathrm{~g}$ fresh weight in the treated one; catechin from $8.7 \mathrm{mg} / 100 \mathrm{~g}$ fresh weight to $9.6 \mathrm{mg} / 100 \mathrm{~g}$ fresh weight: oleuropein form $523 \mathrm{mg} / 100 \mathrm{~g}$ fresh weight to $651 \mathrm{mg} / 100 \mathrm{~g}$ fresh weight. Treating fruits of olive plants 50 days after anthesis had a beneficial effect on fruit size [191] and increased oleuropein depending on the variety by $50 \%$ to $300 \%$ reaching maximal values of $387 \mathrm{mg} / 100 \mathrm{~g}$ fresh weight. The phytoalexin scoparone (6,7-dimethoxycoumarin) accumulated in fruits of tangelo Nova, Citrus aurantium, and Citrus paradisi after treatment with Brotomax [192] enhancing their resistance to Phytophthora parasitica. By treatment of cucumber plants with the plant activator "Milsana", the activity of chalcone synthase was induced resulting in a subcellular accumulation of a defense-related C-glycosyl flavonoid after infection by fungal pathogens [193-195]. Some plant activators may cause a wound-response at the surface which may include an accumulation of phenolic compounds. This was shown in a model experiment using surfactants [196].

Cytokinin: Several studies revealed promotion of phenylpropanoid bisoynthesis and accumulation in plant tissues by the action of cytokinins with an enhancement of PAL activity [197,198], an accumulation of total phenolics [199,200] and anthocyanins [201-204]. Cytokinin induced the accumulation of flavanones in Prunus callus cultures and phloem tissues of cherry shoots and alters the flavonoid profile of these tissues [166,206] (Table 8). An about 20\% increase of the antimicrobial polymethoxyflavones (nobiletin, sinensetin, heptamethoxyflavone, tangeretin) was induced in the outermost tissue (flavedo and exocarp) of tangelo Nova fruits by treating with 6-benzylaminopurine. This application also enhanced the resistance of the fruit to Phytophthora citrophthora by $60 \%$.

Gibberellin $G_{3}$ : Treatment of grapevine Vitis vinifera flowers with a $\mathrm{GA}_{3}$ solution (20 ppm) influenced the phenolic profiles of the wine [207]. The response was not uniform among the varieties tested. The Hungarian cv 'Kadarka' showed strongest response with an increase of phenylpropanoids and flavonols by $52 \%$ and of anthocyanins by $229 \%$ as compared to wine from the non-treated control. This effect may be indirectly attributed to the altered growth and fruit set thus preventing infection by Botrytis [207]. More direct effects of gibberellins were recognized in tissue culture systems, where a decreasing effect of this hormone was observed [203,208-210]. Treatment of excised lettuce hypocotyls with $\mathrm{GA}_{3}$ suppressed PAL activity [211]. 
Table 8. Changes of flavonoid concentrations (\% of untreated controls) in the inner bark (phloem) of Prunus avium shoots as a response to benzyladenine application. Data from [206].

\begin{tabular}{|l|c|c|}
\hline Prunus avium cultivar & $\begin{array}{c}\text { Naringenin } \\
\text { 7-glucoside }\end{array}$ & $\begin{array}{l}\text { Chrysin } \\
\text { 7-glucoside }\end{array}$ \\
\hline Burlat & 130 & 98 \\
Sekunda & 150 & 96 \\
Kassins & 180 & 70 \\
Roße Schwarze Knorpelkirsche & 200 & 70 \\
Abels Späte & 220 & 80 \\
Büttners & 250 & 75 \\
Bigarreau von Ordingen & 280 & 78 \\
Delta & 295 & 90 \\
Königskirsche & 300 & 92 \\
Sam & 320 & 88 \\
Van & 320 & 75 \\
\hline
\end{tabular}

Ethene: Ethene has been known for a long time as an inducer of phenylpropanoid biosynthesis which may be related to a general wound and/or stress response. An ethene related increase of PAL activity was described for instance by [212-215] and an ethene induced accumulation of anthocyanins was described by [216-218]. The biosynthesis of anthocyanins and chlorogenic acid in ripening apple fruits may depend to some extent on the action of ethene since treatment of 'Fuji' apples with the ethene releasing agent ethephon enhanced activity of PAL and of chalcone isomerase as well as red peel color [219]. This treatment also stimulated ACC-oxidase activity and ethene formation indicating an effect on fruit ripening. When ethene receptors were blocked by 1-MCP (1-methylcyclopropene) the accumulation of phenolic compounds in apple fruits was impeded [220]. This observation is contradictory to the findings of Arakawa et al. [221] who proposed an ethene independent UV-B light inducible anthocyanin biosynthesis in apple fruits. The colouration of sweet cherries and the biosynthesis of chlorogenic acid in these fruits seem to be independent from ethene regulation [222].

Methyl-Jasmonate: Wang et al. [223] treated ripening raspberry fruits with methyl jasmonate which resulted in an increase of soluble sugars and a decrease in organic acids. The fruits of variety 'Autumn Bliss' also showed significant changes in flavonoid and ellagic acid contents. Flavonols (glycosides of quercetin and kaempferol) increased from 9.6 to $12.2 \mu \mathrm{g} / \mathrm{g}$ fresh weight, anthocyanins (glycosides of cyanidin) from 550 to $700 \mu \mathrm{g} / \mathrm{g}$ fresh weight and ellagic acid from 28 to $39 \mu \mathrm{g} / \mathrm{g}$ fresh weight. Schreiner and Huyskens-Keil [42] listed stimulating effects of postharvest treatments with methyl jasmonate on the flavonoid formation in apple, potatoes, guava, mango, banana and papaya.

Benzothiadiazole: The plant activator, benzo-(1,2,3)-thiadiazole-7-carbothioic acid $S$-methyl ester (BTH), when sprayed on grape berries cv. Merlot at the end of veraison, led to a more than doubled anthocyanin content in the grape berry skin extract at harvest [224].

Bioregulator Prohexadione-Ca: Among those agents activating plant defence the bioregulator prohexadione- $\mathrm{Ca}$ is a unique case since it is probably not acting via signalling pathways. Prohexadione-Ca reduced fruit set and berry weight of grapevine [225] and retards shoot growth of apples and pears by inhibition of the biosynthesis of hormonally active gibberellin [226]. 
Prohexadione-Ca is acting as a structural mimic of 2-oxoglutarate, and according to this property, it is able to inhibit dioxygenase enzymes, which require 2-oxoglutarate as a co-substrate [226]. Such enzymes are not only involved in formation of gibberellins but also in flavonoid biosynthesis [61]; and hence, prohexadione-Ca is able to alter flavonoid metabolism (Figure 6). As a consequence of this inhibition, several plants are able to re-direct accumulating metabolites towards unusual deoxyflavonoids [227-232] which show phytoalexin-like properties against several plant pathogens [233]. Novel flavonoids are formed in young leaves of apple [227,228] and pear [234] as well as in grapevine leaves and berries [230,235]. Even though for practical application in grape production the influence of prohexadione-Ca on the hormonal balance of the plant must be considered, which may lead, for instance, to reduced berry size and cluster compactness, the bioregulator can be applied as a tool to change the flavonoid composition of grapevine tissues. The mechanism of prohexadione-Ca action is not restricted to a redirection of the natural biosynthetic pathway leading to the back pressure at the level of flavanones and to the transient activation of an alternative pathway towards the formation of deoxycatechin (Figure 8). This disturbance of the metabolic balance is further characterized by an increase of transcripts of the key enzymes PAL and CHS [232] (Figure 2).

Figure 8. Transient alteration of flavonoid biosynthesis in young apple leaves treated with the bioregulator prohexadione-Ca. The newly formed 3-deoxycatechin luteoliflavan and the constitutive intermediary metabolite eriodictyol 7-glucoside accumulate most in the very young leaf no. 1 whereas the subsequent, older leaves at the shoot show weaker response. Data redrawn from [232].
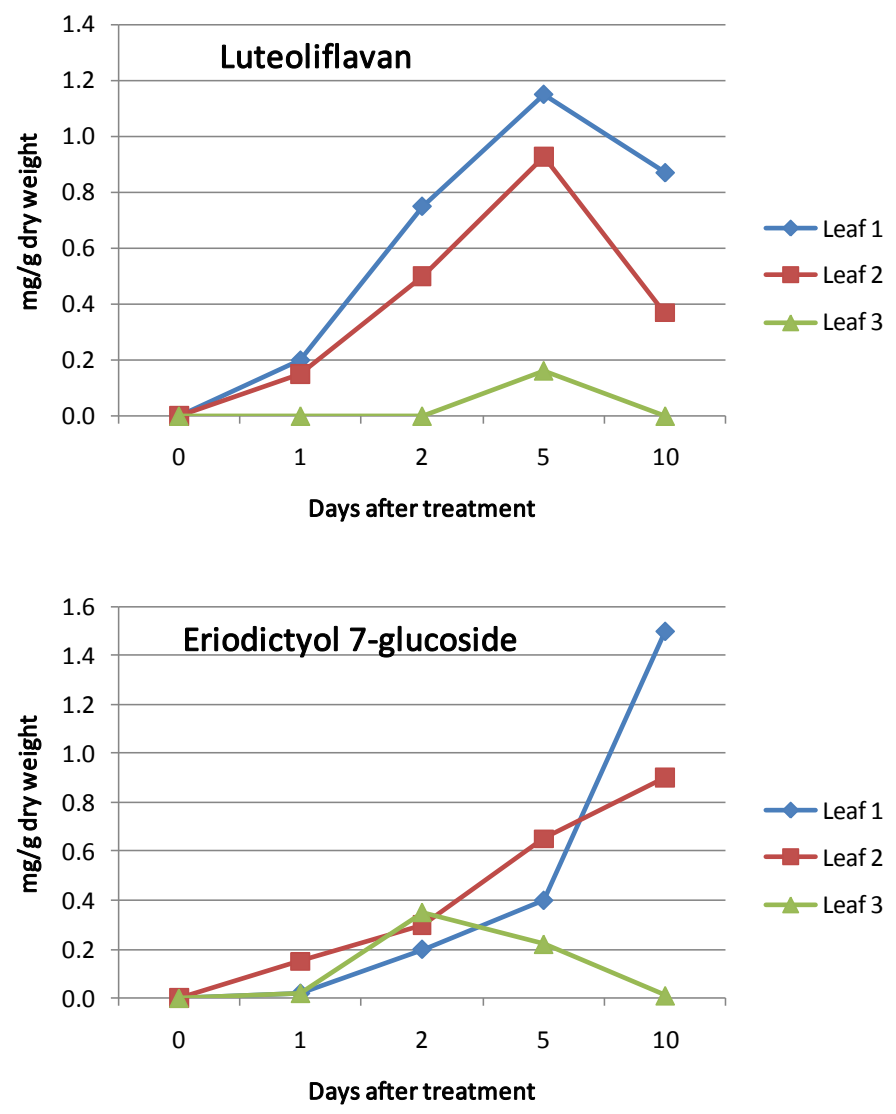


\section{Mechanisms}

\subsection{Interacting Metabolic Pathways and Trade-offs}

The mechanisms involved in the targeted accumulation of phenolic compounds in plants are complex and depend on the biosynthetic pathway to be controlled, on its localization and compartmentalization. Furthermore, diverse signal chains may be involved and the efficiency of measures depends on the accessibility of the respective target. Each primary signal such as abiotic or biotic elicitors will be followed by secondary messengers and an activated signal chain [236] inducing expression of genes, transcription to enzymes and formation and storage of metabolites. A prerequisite for accumulation of high amounts of phenolic compounds is the availability of resources and metabolic precursors from the primary metabolism.

Carbohydrate availability is a prerequisite for phenylpropanoid accumulation. When apple skin pieces were floated with sucrose, anthocyanins increased [237]. The accumulation of chlorogenic acid, catechin and quercetin 3-glucoside in stressed cherry leaves was associated with an accumulation of starch representing a potent carbohydrate pool [168]. Prunus callus cultures produced increasing amounts of flavanones and flavanols with increasing supply of sucrose in the growing medium [166]. In vivo apple shoot tip cultures also showed a pronounced accumulation of flavonoids. In that case it was flavanols and quercetin-glycosides [238]. Carter et al. [239] found in experiments on Lotus corniculatus that an elevated atmospheric level of $\mathrm{CO}_{2}$ increased the concentrations of nonstructural carbohydrates in the leaves correlating with higher concentrations of condensed tannins. Thus, tradeoffs between plant growth and secondary metabolism may counteract with the management of phenolic compounds for agricultural purpose. Underlying hypotheses were recently commented by Matyssek et al. [240].

The accumulation of phenolic compounds in plant tissues under stress conditions may be explained by the action of elicitors stimulating signal chains towards biosynthesis and accumulation of metabolites. Another mechanism behind a stress related enhancement of phenylpropanoid biosynthesis may be driven by a deficiency in reduced pyridine nucleotides (NADPH). In that case, it is supposed that the pentose phosphate pathway is stimulated for providing NADPH thus releasing substrates for shikimate and phenylpropanoid biosynthesis. In model experiments using methylene blue for reconverting the reduced nucleotide to its oxidized form, anthocyanin formation was increased in apple [237] and flavanone accumulation took place in Prunus callus [167]. However, an inhibition of the citrate cycle was not effective for channeling hexose molecules via the pentose phosphate pathway towards the anthocyanin biosynthesis in apple [241].

An interesting link between primary and secondary metabolism was recently discussed by Lattanzio et al. [242] which couples the accumulation of the stress metabolite proline with the energy transfer towards phenylpropanoid biosynthesis via the oxidative pentose phosphate pathway [243]. Under several conditions of stress (pathogen infection, nutrient deficiency), the plant is forced to accumulate a large quantity of free proline. Its synthesis is accompanied by the oxidation of NADPH. An increased $\mathrm{NADP}^{+} / \mathrm{NADPH}$ ratio is likely to enhance activity of the oxidative pentose phosphate pathway providing precursors for phenolic biosynthesis via the shikimic acid pathway. The alternating oxidation of NADPH by proline synthesis and reduction of $\mathrm{NADP}^{+}$by the two oxidative steps of the 
oxidative pentose phosphate pathway serve to link both pathways and thereby facilitate the continuation of high rates of proline synthesis during stress and lead to a simultaneous accumulation of phenolic compounds. Furthermore, it was shown that an application of proline to the nutrient medium of in vivo grown oregano plants elicited the accumulation of rosmarinic acid and other phenolic compounds in that plant [244]. It is suggested that mitochondrial proline oxidation could drive the oxidative pentose phosphate pathway by recycling glutamic acid into the cytosol to generate a proline redox cycle.

\subsection{Regulatory Elements}

The regulation of the biosynthesis of phenolic compounds is complex and in part undertaken by spatial organization and subcellular channeling. The consecutive enzymes of phenylpropanoid and flavonoid biosynthesis are supposed to be organized into linear or globular multienzyme complexes that can be associated with membranes or form metabolons [57,245,246]. Subcellular transport and channeling of metabolites functions with the aid of transporters and vesicles which are co-regulated with structural genes [247,248]. The enzymes are often present as multiple isoforms with varying subcellular or tissue-specific localization or different substrate specificities [245]. The corresponding structural genes are arranged as multigene families [251]. Single members of these families are differently regulated by transcription factors as well as by environmental clues [82]. Additionally some members are also differently expressed in different organs and tissues [249].

Transcriptional regulation is the major controlling step for secondary metabolite pathways [248,252-254]. The transcription factors involved in regulating anthocyanin and proanthocyanidin biosynthesis of Arabidopsis were identified as interacting MYB and bHLH type activators or repressors of the biosynthetic genes. Additionally, WD40 proteins are assisting the process. Different sets of interacting transcription factors were suggested to regulate genes encoding early or late biosynthetic steps, respectively [255,256]. The accumulation of phenolic compounds may be linked with the control of several other morphogenic and physiological processes [248]. The WD40 and HLH regulators seem to be involved in multiple processes whereas different MYB proteins act more specifically to regulate specific pathways. Transcription factors may therefore play a key role in coordinating secondary metabolism with plant differentiation and development [257,258]. For instance, a MYB factor found to be active in strawberry fruits may repress transcription in order to balance the levels of anthocyanin pigments produced at the late stages of strawberry fruit maturation [258]. A regulatory network of negative and positive feedback of gene expression might control and fine-tune the biosynthesis of anthocyanin and proanthocyanidin in Arabidopsis [259]. MYB type transcription factors were also shown to mediate environmental impacts such as mineral nutrient depletion as well as high light intensity on anthocyanin formation [146].

Some knowledge could also be gained on the regulation of anthocyanin accumulation in apples. Evidences that anthocyanin biosynthesis in apple skin depend on mRNA formation were discussed some times ago by Faust [138] who inhibited anthocyanin formation by several antibiotics. Meanwhile it is well understood that during apple fruit ripening and coloration, most of the structural genes of anthocyanin biosynthesis are induced and contribute to increase of red pigments [260-262]. It is further known that UV-B irradiation of the fruits and low temperatures increased the enzymatic 
activities of phenylalanine ammonia lyase and chalcone isomerase as well as the transcript levels of CHS, FHT, DFR, ANS, and UFGT [263-265]. Anthocyanin concentrations were found to positively correlate with UFGalT activities in fruit peel [75]. Environmental effects on the red pigmentation of apple fruits can be attributed to the function of transcription factors. A transcription factor MdMYBA was identified which controls the anthocyanin biosynthesis and is inducible by UV-light and cold temperatures [265]. Its expression is specifically regulated depending on the tissue and the variety with a higher expression in a deep-red variety as compared to a pale-red one. Based on these results on the MYB transcription factors in apple, there could be at least two loci of anthocyanin-related MYB transcription factors in apple, one corresponding to the coloration of the cortex of redfleshed cultivars and the other to the skin color of white-fleshed cultivars. The anthocyanin promoting effect of cold night temperatures may be supported by a reduced loss of sugars through respiration, resulting in a flow of metabolic precursors towards the biosynthesis of anthocyanins [88]. This expression pattern in apple differs from that in grape (Vitis vinifera and V. labruscana), in which UFGT induction during anthocyanin accumulation is a key regulatory step in the development of red coloration [266]. In grape, two kinds of MYB transcription factors regulate phenylpropanoid biosynthesis and show different expression patterns during berry ripening [267,268].

\section{Managing Phenol Contents by Plant Breeding and Selection}

The creation of new varieties of a given crop plant is a powerful tool to enrich our food with beneficial secondary metabolites and to increase the plant's resistance against pathogens and pests or for utilizing any other advantage of a phenol-rich plant. This goal can be achieved by classical breeding if natural resources of high diversity are available. In the last century, classical breeding methods were applied to create ornamental plants with a vast diversity of flower colors based on profiles of anthocyanins with a range of flavonoid co-pigments (e.g., [269]), of aurones and chalcones $[56,270]$. The driving force for research on flavonoids and in particular on anthocyanins may have been their brilliance as flower pigments in ornamentals. The work done on flower colors gave initial insight into the genetics and biosynthesis of flavonoids [271,272]. This formed the basis of our current knowledge on molecular biology and regulatory genes [273,274].

\subsection{Genetic Engineering}

Outlines of different approaches for directing the flavonoid biosynthesis in crop plants by genetic engineering were presented by [275-278]. The most prominent strategies are shortly explained using tomato as an example. In order to improve the content of phenolic compounds as additional nutraceuticals beside the carotenoids being the main beneficial ingredients of tomato fruit, several strategies were developed and at least partially realized. For getting high-flavonol tomatoes the following transgenic strategies were attempted:

- overexpression of petunia chalcone isomerase

- heterologous expression of the maize transcription factor genes $L C$ and $C 1$

- fruit-specific RNAi-mediated (RNA interference) suppression of the regulator gene DETI 
Novel pathways using metabolites of phenylpropanoid and flavonoid biosynthesis have to be introduced for getting tomato fruits containing isoflavones and stilbenes. This was realized by using the following strategies:

- overexpression of a soybean isoflavone synthase gene

- overexpression of a stilbene synthase gene

Overexpression of petunia chalcone isomerase in tomato results in 78 fold increased levels of flavonols, mainly rutin, in the skin [279].

Simultaneous expression of the two regulatory genes $L C$ and $C l$ was required and sufficient to upregulate the flavonoid pathway in transgenic tomato fruit flesh [280]. The ripe fruits of the transgenic $L C / C 1$ tomatoes accumulated high levels of flavonols. After hydrolysis of the glycosides, the concentrations of the aglycone kaempferol rose from about $2 \mathrm{mg} / \mathrm{kg}$ fresh weight in the non-transgenic fruit up to $60 \mathrm{mg} / \mathrm{kg}$ fresh weight in the transgenic ones. The corresponding values for the flavanone naringenin were about $20 \mathrm{mg} / \mathrm{kg}$ fresh weight and $60 \mathrm{mg} / \mathrm{kg}$ fresh weight. The expression of the specific anthocyanin regulating snapdragon transcription factors, Del and Ros1, induced the accumulation of high levels of anthocyanins in tomato [281]. The reasons underlying the success of this regulatory combination are partly explained by high levels of gene induction and by activating a broad spectrum of genes. DET1 (DE-ETIOLATED1) is another regulatory gene which represses several signaling pathways controlled by light. Mutations in this gene are responsible for higher pigmentation of tomatoes due to elevated levels of both flavonoids and carotenoids. Using fruitspecific promoters combined with RNA interference (RNAi) technology tomato plants could be generated with degradation of DET1 transcripts in their fruits [282]. In these transgenic lines fruits were found with concentrations for chlorogenic acid, for quercetin glycosides and for naringeninchalcone more than doubled as compared to the wild type control. Other quality parameters such as fruit size and soluble solids were largely unchanged. When tomato plants were transformed with a soybean isoflavone synthase (GmIFS2) under the control of the cauliflower mosaic virus $35 \mathrm{~S}$ promoter, substantial amounts of genistin (up to $90 \mathrm{nmol} / \mathrm{g} \mathrm{FW}$ ) were found in leaves, while the levels were marginally detectable (less than $0.5 \mathrm{nmol} / \mathrm{g} \mathrm{FW}$ ) in fruit peels [283]. In potatoes a 4-fold increase of the anthocyanins derived from petunidin and pelargonidin could be achieved by overexpression of a DNA encoding dihydroflavonol 4-reductase (DFR) [284]. A stilbene synthase gene was successfully introduced in apple plants [285] and the fruits produced the stilbene resveratrol-glucoside piceid [286].

Commercially relevant are the transgenic ornamentals which are already introduced into the market. Since the first transgenic petunia with pelargonidin type flower color was generated [287] many efforts were achieved. Of special interest are blue colored flowers such as the blue carnation and the blue rose where the shift towards the blue color was realized by increasing the B-ring hydroxylation pattern and accumulation the delphinidin type anthocyanins as a result of flavonoid 3',5'-hydroxylase gene overexpression [288]. A general enhancement of anthocyanin production in petunia could be achieved by altering competition for substrate between flavonol synthase and dihydroflavonol 4-reductase [289]. On the basis of pigment and co-pigment analyses of Kalanchoë blossfeldiana varieties the introduction of acyl transferases is proposed as an approach to flowers with bluish colors [290].

Metabolic engineering strategies rely on the current knowledge. Thus, if the knowledge on biosynthetic pathways is incomplete, a proposed strategy may fail. One exciting example is the attempt to create red forsythia flowers by introducing dihydroflavonol 4-reductase and anthocyanidin synthase 
genes [291] which results in at that time unexplainable accumulation of epicatechin instead of anthocyanins. Some months later, this observation became explained by the discovery of the ANR enzyme reducing cyanidin to epicatechin [292].

In an outline on molecular breeding for color, flavor and fragrance Gutterson [293] stated in 1993 that "the applications of molecular breeding in the near term will probably be few, and they will be focused on those crops where the economic reward can justify the technical investment cost". This may remain true for a while since transformation techniques and regeneration of transformed tissues to complete plants still have to be developed.

\subsection{Diversity in Existing Varieties as a Prerequisite for Breeding}

In a trial with strawberries which were cultivated under several varying environmental conditions and cultivation methods like conventional and organical it could be shown that the variability of the phenolic contents among the varieties was much higher than the effect of cultivation techniques to be expected [132]. Variety and provenience dependent variations in phenol concentrations of apple were formerly summarized [294]. In a recent study on cider apples, pronounced concentration variability was found for most phenolic compounds [295]. The values in the pulp ranged from 48 to $227 \mathrm{mg} / \mathrm{kg}$ fresh weight for epicatechin, from 672 to 3,041 for procyanidins, from 61 to 724 for chlorogenic acid, 7 to 56 for phloridzin, 0.5 to 5 for quercitrin. The corresponding concentrations in the peel were: epicatechin, 11-81 mg/kg fresh weight; procyanidins, 360-929 mg/kg fresh; chlorogenic acid, 5-67 mg/kg fresh, phloridzin 7-123 mg/kg fresh; quercitrin, 3-29 mg/kg fresh. The flavonol content (quercetin glycosides) of commercial tomato fruits belonging to the species Lycopersicon esculentum reaches around $1.6 \mathrm{mg}$ per fruit. A screening of wild species of the genus Lycopersicon revealed a widespread occurrence of key enzymes of the flavonoid biosynthesis [296] and L. esculentum $\mathrm{x}$ L. penelli accumulate up to $18 \mathrm{mg}$ flavonols. Blueberry genotypes show a variation of the anthocyanin concentration ranging from 0.5 to $2.5 \mathrm{~g} / \mathrm{kg}$ fresh weight [297]. Analyses of flavonols and hydroxycinnamic acids resulted in values between 0.2 and $1.2 \mathrm{~g} / \mathrm{kg}$ fresh weight but with a negative correlation to fruit weight. The content of phenolic compounds varied widely between raspberry cultivars [85]. The quercetin content ranged from 0.32 to $1.55 \mathrm{mg} / 100 \mathrm{~g}$ fresh weight, ellagic acid from 38 to $118 \mathrm{mg} / 100 \mathrm{~g}$ fresh weight, anthocyanins from close to 0 (yellow cultivars) to $51 \mathrm{mg} / 100 \mathrm{~g}$ fresh weight. In a raspberry breeding programme the parent varieties Rubus strigosus 'Latham' and R. idaeus 'Glen Moy' exhibited $302 \mu \mathrm{g} / \mathrm{mL}$ and $206 \mu \mathrm{g} / \mathrm{mL}$ of cyanidin 3-sophoroside, respectively, as the main anthocyanin of the juice. In the progeny consisting of 188 plants, the concentrations of this pigment ranged from $39 \mu \mathrm{g} / \mathrm{mL}$ to $716 \mu \mathrm{g} / \mathrm{mL}$. Compared to this broad variation, environmental effects on the anthocyanin level of raspberries were only marginal [298]. Anthocyanins in cranberry fruits from different genotypes ranged between 19.8 and $65.6 \mathrm{mg} / 100 \mathrm{~g}$ fresh weight [299]. A screening of blackberry varieties [300] revealed concentrations of anthocyanins from 131 to $256 \mathrm{mg} / 100 \mathrm{~g}$ fresh weight, of procyanidins from 3.3 to $27 \mathrm{mg} / 100 \mathrm{~g}$ fresh weight, of ellagitannins from 7.7 to $27 \mathrm{mg} / 100 \mathrm{~g}$ fresh weight, of flavonols from 4 to $12 \mathrm{mg} / 100 \mathrm{~g}$ fresh weight. Spinach breeding lines show a broad range of special spinach-flavonoids from 0.8 to $2.2 \mathrm{mg} / \mathrm{g}$ fresh weight [301]. In a buckwheat (Fagopyrum sp.) breeding programme interspecific hybrids could be selected which exceed the parents in producing the bioactive flavonol rutin which is a strong quality factor of the buckwheat 
flour [302]. The powerful biosynthesis of catechins and propelargonidins characterising the species Fagopyrum homotropicum was redirected towards rutin formation in some hybrids with the common F. esculentum (Figure 9).

Figure 9. Phenolic compounds in buckwheat seeds ( $\mathrm{mg} / \mathrm{g}$ dry weight) from a breeding programme using Fagopyrum esculentum (F. esc.) and F. homotropicum (F. hom.) as parental plants with extraordinary contents of the flavonol rutin in interspecific hybrids. Data from [302].
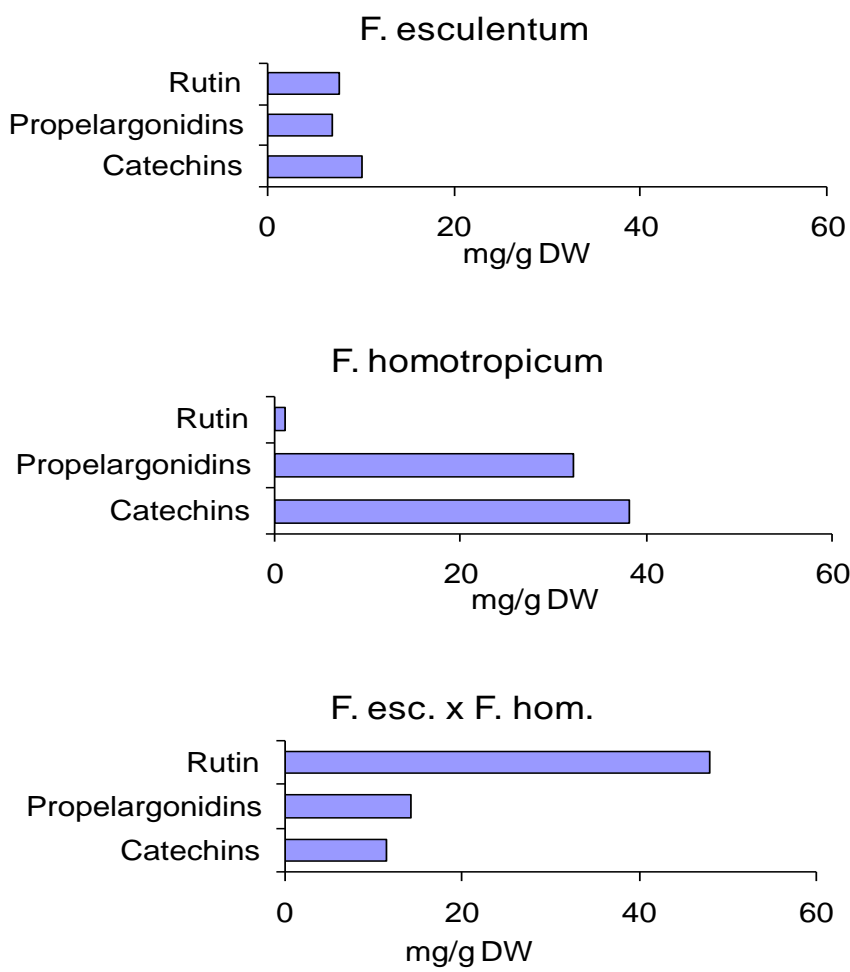

\section{Constraints and Physiological Feedback}

For optimized triggering the accumulation of target phenolic compounds in crop plants information is needed on the complete reaction chain starting with the primary elicitor and its effects on secondary signals followed by gene expression, transcription and activity of related enzymes and ending with the formation of metabolites. Possible side effects on other biosynthetic pathways must be taken into account. As described above (Section 3), a couple of tools are available and are practiced to a certain extent. However, a generally valid prediction of the plants' response to a newly applied inductive method is scarcely possible and must take into account that the secondary metabolism of the respective plant is embedded into growth and differentiation. It may help to clarify first which role a given phenolic compound may play in the plant. One important function of flavonoids is the activity of a sunscreen [77,92,93] (and as photoprotective agents [303,304]). Many phenolic compounds act as resistance factors [52] with a multifunctional role [305] and are involved in adaptation to environmental stress conditions such as low or high temperatures [97,306]. These tasks imply the formation and accumulation in those plant tissues which are exposed to the environment and which 
have to be protected. Regarding red skinned apples, light exposure is leading to the desired result. UV irradiation of lettuce, however, may increase the phenolic levels in the outer leaves of a lettuce head which normally will not be eaten but thrown into the waste.

Depending on the mechanisms of induction or elicitation of the stimulation of biosynthesis it is furthermore essential to know if the respective constitutional pathway is active and if the constitutive enzymes are already working. This may be modified by development and differentiation of the plant or at least the respective organ since the phenylpropanoid and flavonoid pathways are integrated into these processes. For instance, UV-B induced flavonol accumulation in Petunia leaves declined with increasing leaf age [93]. With regards to a possible activation of the deoxyflavanol pathway by prohexadione-Ca it was found that only very young leaves exhibit a strong response (Figure 6). In older leaves the flavonoid pathway seems to be "silent" and cannot be activated by the bioregulator [232]. A similar temporary effect of the bioregulator treatment was also shown for grapevine berries and leaves [307]. The characteristic response of strawberry fruits to prohexadione-Ca treatment with the accumulation of the flavanone eriodictyol 7-glucoside and the 3-deoxycatechin luteoliflavan could only be induced at specific ontogenetic stages [235]. While flowers and mature green and red fruits only weakly responded to the treatment, the stage of small green fruit accumulated the novel compounds to a high level indicating a strong flavonoid biosynthesis at that developmental stage of the fruit.

If the prerequisite of the available and active enzymes is fulfilled a further constraint could appear if resources are limited or trade-offs exist. A negative relationship between apple shoot growth and accumulation of phenolic compounds was reported formerly [308]. In in-vitro studies, this effect could be strengthened by high nitrogen supplement which dampens the prohexadione-Ca induced biosynthesis of 3-deoxycatechin in apple shoots [309] (Figure 10). In grapevine, only a moderate $N$-nutrition allowed a response to UV-light with regards to the accumulation of quercetin glycosides [310].

Figure 10. Effect of nitrogen nutrition on the prohexadione-Ca induced accumulation of 3-deoxycatechin (luteoliflavan). Redrawn from [309].

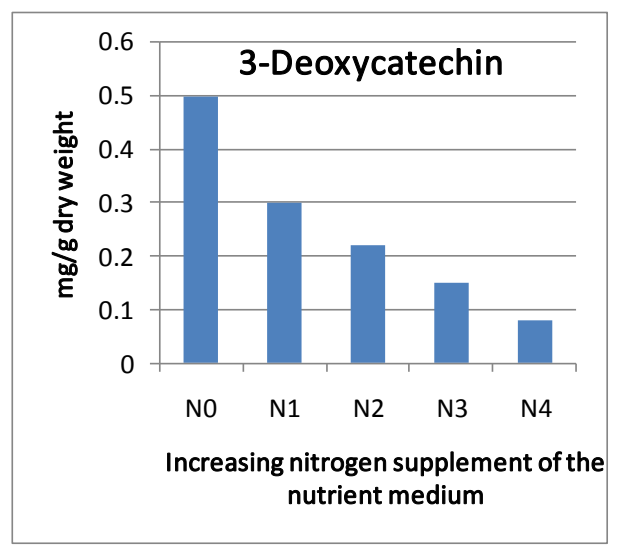

When the goal of an enrichment of phenolic compounds was reached it has to be anticipated that a physiological feedback may occur. The physiological activity of phenolic compounds with particular roles in growth related processes is debated since long [311,312]. Ferulic acid could act as an auxin 
antagonist during root formation of apple tree [313] and could affect hypocotyl growth of Amaranthus seedlings [314]. Naringenin 7-glucoside was isolated from peach buds and identified as a growth inhibiting factor possibly related to bud dormancy [315-317]. The differential effects of phenolic compounds on the activity of IAA-oxidases are well established with mono-phenols being promoting and catechol-type phenols being inhibiting [318-321]. The preservation of indoleacetic acid by catechin supplement in the nutrient solution of Prunus callus cultures may be responsible for pronounced changes in tissue differentiation and metabolism [322]. The effect of different cinnamic acid derivatives on indole acetic acid oxidation by peroxidase was intensively studied [323]. Interaction with plant hormones may explain the observed growth promotion of callus cultures by chlorogenic acid on auxin-free media [324,325]. It is obvious that flavonoids may regulate auxin transport in plants [326]. Beside that effect on the IAA-metabolism, phenolic compounds may also affect the basipolar transport of auxin. A stimulation of auxin movement was found for naringin [327]. An inhibition of oxidative phosporylation and of membrane bound ATP-formation was found for some flavonoids, such as naringenin [320,328,329]. Novel functions of flavonoids will be deduced from recent investigations on the accumulation of flavonoids in the nuclei of a wide range of species [185,330-332]. It is stated that nuclear flavonoids bound to histones are involved in epigenetically regulated modification of chromatin [333].

What may happen if phenolic compounds leave their vacuolar compartment? In incompatible graft unions of cherries, naringenin 7-glucoside was found to accumulate as a stress metabolite [334]. It could be shown that such an abnormal accumulation may affect cellular differentiation and secondary metabolism after leaching from its main compartments, the vacuole or cytoplasmic vesicles, in case of further stress related membrane dysfunction. When Prunus avium and P. cerasus cells were treated with naringenin 7-glucoside, vessel differentiation was inhibited and instead of this, highly vacuolated cells were formed with a strong biosynthesis of catechins and proanthocyanidins [167].

As long as phenolic compounds are put away in vacuoles or vesicles they may not exhibit significant effects on any physiological process of the respective plant tissue. However, in stress situations membrane integrity may be affected [106], thus, their phenolic content may be released and come in contact with the metabolic and regulatory machinery of the cell [335]. The cellular differentiation of Prunus callus cultures could be reorganized by application of naringenin 7-glucoside via the nutrient solution $[106,167]$. The response of the plant tissue on the invasion of an unusual or foreign phenolic compound depends on its chemical structure and physiological activity. Whereas naringenin 7-glucoside increased membrane permeability, reduced tissue growth, and caused a change in cellular differentiation [167,336], the flavan-3ol catechin was found to stabilize membranes and counteracted a growth inhibiting effect of abscisic acid [337]. Catechin was furthermore shown to promote growth of several plant tissues, including Prunus callus [322] and in pedicels of beech Fagus sylvatica [337]. From the viewpoint of a plant grower both positive and negative effects may appear. The possible antioxidant activity of phenolic compounds may be designated as a positive one. The detrimental effect of the free radical releasing paraquat molecule could be reduced by catechins in several plant models [338].

Morphological effects induced by the flavones isovitexin were also reported to occur in a nonglycosylating Silene pratensis genotype [102]. Furthermore, allelopathic plant-plant and plant-microbe interactions [339] may be expected. Phenolic compounds in root exudates of several plants are key 
signaling components in the symbiosis between different host plant species and their ecto- or endosymbiotic fungal partners. Furthermore, upon interaction with their fungal symbiotic partners the metabolic profiles of the host plant roots can be changed. [340-350]. Therefore, cultivation techniques and environmental factors affecting the phenolic profiles of such plants may influence symbiosis and by that indirectly plant growth as well.

\section{Conclusions}

Several approaches for managing the contents and profiles of phenolic compounds in crop plants are presented. Among the cultivation technologies, the application of controlled mild stress conditions is sometimes propagated and several ideas are born from in-vitro experiments using tissue cultures or young seedlings but the up-scaling to a marketable produce often remains obscure. Results obtained by model experiments have to be thoroughly interpreted and carefully extrapolated to commonly used production methods.

The main route of targeted phytochemical farming (Figure 11) starts from the environmental factors modified by agricultural technology which must be recognized by the plant requiring sensitivity of the respective tissue. This step must be followed by a metabolic response depending on the expression of related genes which has to be transcribed to functional enzymes. Metabolic channeling may then direct to the accumulation of the target product if not disturbed by feedback mechanisms or by further metabolism or degradation. The farmers' activities and/or changing environments also control growth and differentiation of the plant, thereby modifying precursor pools of the targeted secondary metabolism. The requested bioactive compound may exhibit physiological activity, thus affecting plant development and ecological performance. Increased resistance to biotic and/or abiotic stress situations may crop up as an added value of accumulating phenolic compounds.

Figure 11. Route of targeted pytochemical farming indicating constraints and physiological feed back.

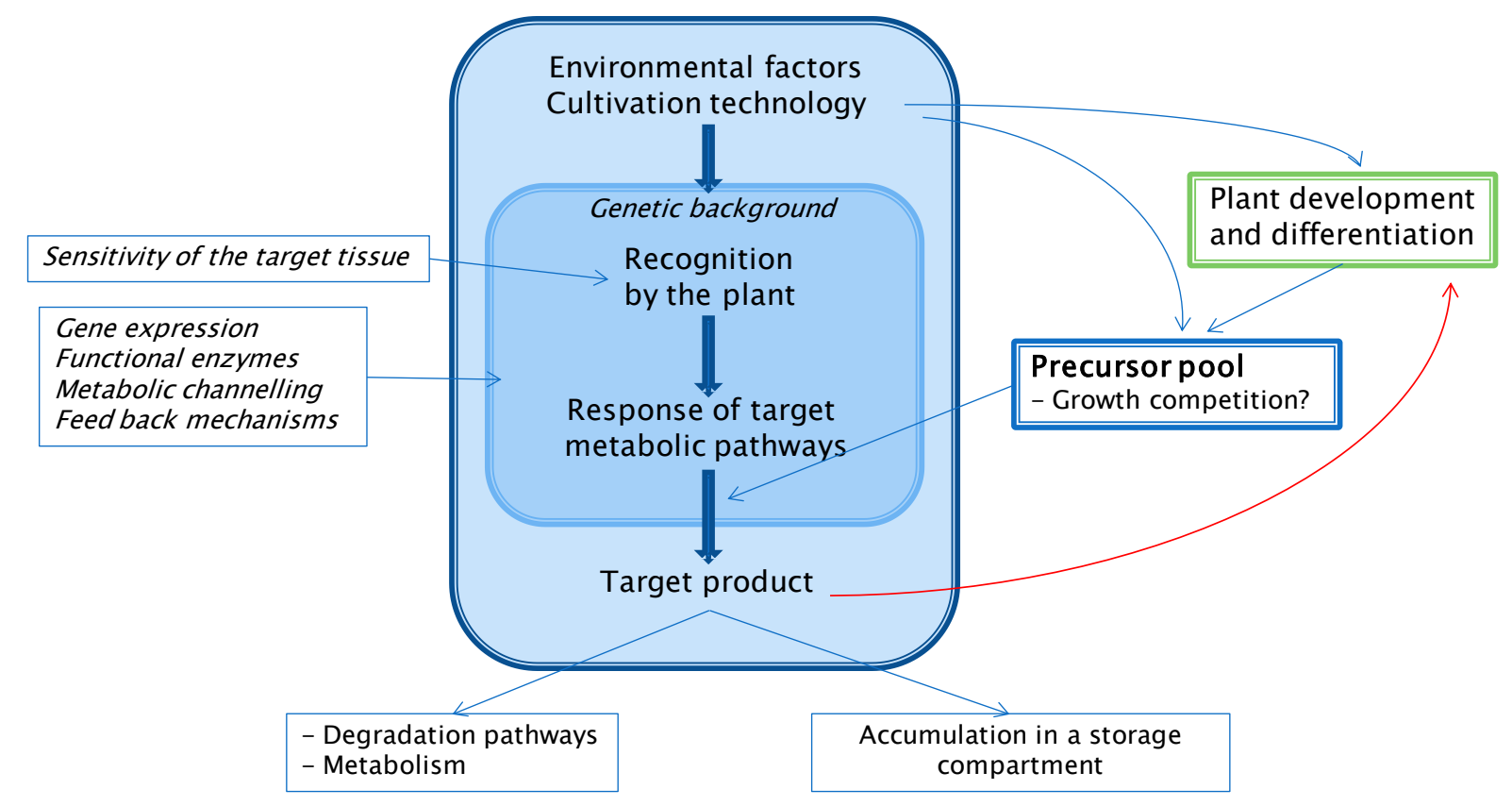


Before such efforts in adapting cultivation technologies can be advised to the plant grower we should know:

- the beneficial effects of target chemicals

- the beneficial concentrations

- for plant resistance

- for human or animal health

- environmental impacts on biosynthesis and metabolism

- the role of the target phytochemicals in the plant.

A further prerequisite is an expected financial return. If a particular phenolic composition and concentration could be achieved, the question is how sustainable is the commercial return? Consumers' attitudes may change or a reappraisal of particular bioactive components may happen based on advances in scientific knowledge. A curious example is the loss of the value of apples' red skin colour as a marker for inner quality. Red coloration of many fruits like apple and strawberries may portend high fruit quality and optimal ripening stage based on the often observed biosynthetic relation to developmental processes in such fruits. High taste quality correlates with red pigmentation of old weakly colored apple cultivars (Figure 3) [74]. This may account for the consumers' preferences since about $50 \%$ of the consumers indicate fruit color as a main selection criterion [351-353]. This contributes to higher prices for apple fruits for instance grown in the mountains of South Tyrol with prices attained by the growers of $45 €$-Cents per $\mathrm{kg}$ as compared to the price for fruits grown in the valley with $35 €$-Cents per $\mathrm{kg}$ [354]. Another study in 1986 revealed a $10 \%$ higher price for 'Roter Boskoop' as compared to the 'Gelber Boskoop' and more than $60 \%$ higher price for red mutants of 'Jonagold' in comparison to the standard 'Jonagold' [355]. The higher economic value, however, enforced the fruit growers and breeders to focus on mutants which accumulate anthocyanins even under low light conditions. Since most of the other fruit characteristics remained unchanged the red skinned mutants replaced the original cultivars to a high extent. This was observed for the old apple varieties 'Gelber Boskoop', 'Gravensteiner', 'James Grieve' which have been replaced by red mutants. Among the new apple varieties 'Jonagold', 'Elstar', 'Gala', 'Braeburn', 'Fuji', 'Topaz', 'Pinova' many red mutants have been selected up to now [356-361]. By that kind of selection the value of the red apple skin as a useful marker for high fruit quality with optimal organoleptic properties is strongly reduced. This could be confirmed for red-skinned mutants of 'Gala' and 'Jonagold' where the correlation between red skin and ripening stage is poor [353]. Nevertheless, the red color of apples is paid for!

Despite such uncertainties with respect to the sustainability of a measure for phytochemical farming, it is inevitable to increase our knowledge on optimization and influencing the composition and enhancement of "bioactive" metabolites in plant foods (namely fruits and vegetables) by breeding (classical methods, genetic engineering), production technology, storage and processing. At the same time, the plant grower should keep an eye on the progress in nutritional science and nutrition medicine which may state the biologic activities of phenolic compounds more precisely. At the moment, it may not be recommended starting the production of plant foods with an attributed enhanced nutritional quality for a common market. However, the production of fresh "functional food" with defined health claims may be favorable for a premium market segment. In future, it may be expected for the global 
market that minimum quality of plant foods will be defined on the base of their content of bioactive components.

\section{Acknowledgements}

This paper is dedicated to Walter Feucht on the occasion of his 80th birthday.

\section{References and Notes}

1. Hertog, M.G.L.; Feskens, E.J.M.; Hollman, P.C.H.; Katan, M.B.; Kromhout, D. Dietary antioxidant flavonoids and risk of coronary heart disease: The Zutphen elderly study. Lancet 1993, 342, 1007-1011.

2. Watzl, B.; Leitzmann, C. Bioaktive Substanzen in Lebensmitteln, 3rd ed.; Hippokrates Verlag: Tubingen, Germany, 2005.

3. Middleton, E., Jr.; Kandaswami, C.; Theoharides. T.C. The effects of plant flavonoids on mammalian cells: Implications for inflammation, heart disease, and cancer. Pharmacol. Rev. 2000, 52, 673-751.

4. Gohil K.; Packer, L. Bioflavonoid-rich botanical extracts show antioxidant and gene regulatory activity. Ann. NY Acad. Sci. 2002, 957, 70-77.

5. Bensath, A.; Ruysnyak, T.; Szent-Györgyi, A. Vitamin nature of flavones. Nature 1936, 138, 789-793.

6. Parrot, J.L.; Canu, P. Les facteurs qui elevent la resistance capillaire. Archs. Int. Pharmacodyn. 1964, 152, 234-248.

7. Pierpoint, W.S. Phenolics in food and feedstuffs: The pleasures and perils of vegetarianism. In The Biochemistry of Plant Phenolics; van Sumere, C.F., Lea, P.J., Eds.; Clarendon Press: Oxford, UK, 1985; pp. 427-454.

8. Rogers, C.R. The nutritional incidence of flavonoids: Some physiological and metabolic considerations. Experientia 1988, 44, 725-733.

9. Clifford, M.; Brown, J.E. Dietary flavonoids and heath-Broadening the perspective. In Flavonoids. Chemistry, Biochemistry and Applications; Andersen, O.M., Markham, K.R., Eds.; Taylor and Francis: Boca Raton, FL, USA, 2005; pp. 319-370.

10. Wiseman, H. Isoflavonoids and human health. In Flavonoids. Chemistry, Biochemistry and Applications; Andersen, O.M., Markham, K.R., Eds.; Taylor and Francis: Boca Raton, FL, USA, 2005; pp. 371-396.

11. Wenzel, U.; Daniel, H. Polypenols and gene expression. In Recent Advances in Polyphenol Research; Daayf, F., Lattanzio, V., Eds.; Wiley-Blackwell: Chichester, UK, 2008; Volume 1, pp. 359-378.

12. Rimbach, G.; Melchin, M.; Moehring, J.; Wagner, A.E. Polyphenols from cocoa and vascular health-A critical review. Int. J. Mol. Sci. 2009, 10, 4290-4309.

13. Tapas, A.R.; Sakarkar, D.M.; Kakde, R.B. Flavonoids as nutraceuticals: A review. Trop. J. Pharma. Res. 2008, 7, 1089-1099. 
14. Janisch, K.M.; Ölschläger, C.; Treutter, D.; Elstner, E.F. Simulated digestion of Vitis vinifera seed powder: Polyphenolic content and antioxidant properties. J. Agr. Food Chem. 2006, 54, 4839-4848.

15. Hippeli, S.; Janisch, K.; Kern, S.; Ölschläger, C.; Treutter, D.; May, C.; Elstner, E.F. Antioxidant and immune modulatory activities of fruit and vegetable extracts after "cascade fermentation". Curr. Topics Biochem. Res. 2007, 9, 83-97.

16. Balasundram, N.; Sundram, K.; Samman, S. Phenolic compounds in plants and agri-industrial byproducts: Antioxidant activity, occurrence, and potential uses. Food Chem. 2005, 99, 191-203.

17. Alarcón de la Lastra, C.; Villegas, I. Resveratrol as an anti-inflammatory and anti-aging agent: Mechanisms and clinical implications. Mol. Nutr. Food Res. 2005, 49, 405-430.

18. Renaud, S.; de Lorgeril, M. Wine alcohol, platelets and the French paradox for coronary heart disease. Lancet 1992, 339, 1523-1526.

19. Kahle, K.; Kraus, M.; Richling, E. Polyphenol profiles of apple juices. Mol. Nutr. Food Res. 2005, 49, 797-806.

20. Bitsch R.; Netzel, M.; Carlé, E.; Strass, G.; Kesenheimer, B.; Herbst, M.; Bitsch, I. Bioavailability of antioxidative compounds from Brettacher apple juice in humans. Innov. Food Sci. Emerg. Technol. 2000, 1, 245-249.

21. Chinnici, F.; Bendini, A.; Gaiani, A.; Riponi, C. Radical Scavenging activities of peels and pulps from cv. golden delicious apples as related to their phenolic composition. J. Agric. Food Chem. 2004, 52, 4684-4689.

22. Howell, A.B.; Reed, J.D.; Krueger, C.G.; Winterbottom, R.; Cunningham, D.G.; Leahy, M. A-type cranberry proanthocyanidins and uropathogenic bacterial anti-adhesion activity. Phytochemistry 2005, 66, 2281-2291.

23. Sueiro, L.; Yousef, G.G.; Seigler, D.; Demejia, E.G.; Grace, M.H.; Lila, M.A. Chemopreventive potential of flavonoid extracts from plantation-bred and wild Aronia melanocarpa (Black Chokeberry) Fruits. J. Food Sci. C: Food Chem. Toxicol. 2006, 71, 480-488.

24. Gil, M.I.; Tomás-Barberán, F.A.; Hess-Pierce, B.; Holcroft, D.M.; Kader, A.A. Antioxidant activity of pomegranate juice and its relationship with phenolic composition and processing. J. Agric. Food Chem. 2000, 48, 4581-4589.

25. Wunderlich, S.; Zürcher, A.; Back, W. Enrichment of xanthohumol in the brewing process. Mol. Nutr. Food Res. 2005, 49, 874-881.

26. Espín, J.C.; García-Conesa, M.T.; Tomás-Barberán, F.A. Nutraceuticals: Facts and fiction. Phytochemistry 2007, 68, 2986-3008

27. Lampila, P.; van Lieshout, M.; Gremmen, B.; Lähteenmäki, L. Consumer attitudes towards enhanced flavonoid content in fruit. Food Res. Int. 2008, 42, 122-129.

28. Lea, A.G.H.; Arnold, G.M. The phenolics of ciders: Bitterness and astringency. J. Sci. Food Agric. 1978, 29, 478-483.

29. Matsuo, T.; Shinoharam J.; Ito, S. An improvement of removing astringency in persimmon fruits by carbon dioxids gas. Agric. Biol. Chem. 1976, 40, 215-220.

30. Lea, A.G.H.; Timberlake, C.F. The phenolics of ciders: Effects of processing conditions. J. Sci. Food Agric. 1978, 29, 484-492. 
31. Ölschläger, C.; Milde, J.; Schempp, H.; Treutter, D. Polyphenols and antioxidant capacity of Sorbus domestica L. fruits. J. Appl. Bot. Food Qual. 2004, 78, 112-116.

32. Hufnagel, J.C.; Hofmann, T. Orosensory-directed identification of astringent mouthfeel and bittertasting compounds in red wine. J. Agric. Food Chem. 2008, 56, 1376-1386.

33. Benavente-Garcia, O.; Castillo, J.; Lorente, J.; Ortuno, A.; Del Rio, J.A. Antioxidant activity of phenolics extracted from Olea europaea L. leaves. Food Chem. 2000, 68, 457-462.

34. Barry, T.N.; McNabb, W.C. The implications of condensed tannins on the nutritive value of temperate forages fed to ruminants. Brit. J. Nutr. 1999, 81, 263-272.

35. Tanner, G.J.; Moate, P.J.; Davis, L.H.; Laby, R.H.; Li, Y.G.; Larkin, P.J. Proanthocyanidins (condensed tannin) destabilize plant protein foams in a dose dependent manner. Austr. J. Agr. Res. 1995, 46, 1101-1109.

36. Mueller-Harvey, I. Unravelling the conundrum of tannins in animal nutrition and health. J. Sci. Food Agric. 2006, 86, 2010-2037.

37. Regos, I.; Urbanella, A.; Treutter, D. Identification and quantification of phenolic compounds from the forage legume sainfoin (Onobrychis viciifolia). J. Agr. Food Chem. 2009, 57, 5843-5852.

38. Hoste, H.; Jackson, F; Athanasiadou, S.; Thamsborg, S.M.; Hoskin, S.O. The effects of tanninrich plants on parasitic nematodes in ruminants. Trends Parasitol. 2006, 22, 253-261.

39. Santos-Buelga, C.; Scalbert, A. Proanthocyanidins and tannin-like compounds-nature, occurrence, dietary intake and effects on nutrition and health. J. Sci. Food Agric. 2000, 80, 1094-1117.

40. Parr, A.J.; Bolwell, G.P. Phenols in the plant and in man. The potential for possible nutritional enhancement of the diet by modifying the phenols content or profile. J. Sci. Food Agric. 2000, 80, 985-1012.

41. Schreiner, M. Vegetable crop management strategies to increase the quantity of phytochemicals. Eur. J. Nutr. 2005, 44, 85-94.

42. Schreiner, M.; Huyskens-Keil, S. Phytochemicals in fruit and vegetables: Health promotion and postharvest elicitors. Critical Rev. Plant Sci. 2006, 25, 267-278.

43. de Pascual-Teresa S.; Sanchez-Ballesta, M.T. Anthocyanins: From plant to health. Phytochem. Rev. 2008, 7, 281-299.

44. Martínez-Ballesta, M.C.; López-Pérez, L.; Hernández, M.; López-Berenguer, C.; FernándezGarcía, N.; Carvajal, M. Agricultural practices for enhanced human health. Phytochem. Rev. 2008, 7, 251-260.

45. Ruiz-Rodriguez, A.; Marín, F.R.; Ocana, A.; Soler-Rivas, C. Effect of domestic processing on bioactive compounds. Phytochem. Rev. 2008, 7, 345-384.

46. Amarowicz, R.; Carle, R.; Dongowski, G.; Durazzo, A.; Galensa, R.; Kammerer, D.; Maiani, G.; Piskula, M.K. Influence of postharvest processing and storage on the content of phenolic acids and flavonoids in foods. Mol. Nutr. Food Res. 2009, 53, S151-S183.

47. Wink, M. Plant breeding: Importance of plant secondary metabolites for protection against pathogens and herbivores. Theor. Appl. Genet. 1988, 75, 225-233.

48. Beier, R.C.; Oertli, E.H. Psoralen and other linear furanocoumarins as phytoalexins in celery. Phytochemistry 1983, 22, 2595-2597. 
49. Nigg, H.N.; Strandberg, J.O.; Beier, R.C.; Petersen, H.D.; Harrison, J.M. Furanocoumarins in Florida celery varieties increased by fungizide treatment. J. Agric. Food Chem. 1997, 45, 1430-1436.

50. Schulzova, V.; Hajslova, J.; Botel, P.; Peroutka, R. Furanocoumarins in vegetables: Influence of farming system and other factors on levels of toxicants. J. Sci. Food Agric. 2007, 87, 2763-2767.

51. Hartmann, T. From waste products to ecochemicals: Fifty years research of plant secondary metabolism. Phytochemistry 2007, 68, 2831-2846.

52. Treutter, D. Significance of Flavonoids in Plant Resistance and Enhancement of Their Biosynthesis. Plant Biol. 2005, 7,581-591.

53. Hernandez, I.; Alegre, L.; Van Breusegem, F.; Munné-Bosch, S. How relevant are flavonoids as antioxidants in plants? Trends Plant Sci. 2009, 14, 125-132.

54. Saura-Calixto, F.; Serrano, J.; Goni, I. Intake and bioaccessibility of total polyphenols in a whole diet. Food Chem. 2007, 101, 492-501.

55. Serrano, J.; Puupponen-Pimiä, R.; Dauer, A.; Aura, A.-M.; Saura-Calixto, F. Tannins: Current knowledge of food sources, intake, bioavailability and biological effects. Mol. Nutr. Food Res. 2009, 53, 1-20.

56. Halbwirth, H. The creation and physiological relevance of divergent hydroxylation patterns in the flavonoids pathway. Int. J. Mol Sci. 2010, 11, 595-621.

57. Winkel-Shirley, B. Flavonoid biosynthesis. A colorful model for genetics, biochemistry, cell biology, and biotechnology. Plant Physiol. 2001, 126, 485-493.

58. Gross G. From lignins to tannins: Forty years of enzyme studies on the biosynthesis of phenolic compounds. Phytochemistry 2008, 69, 3018-3031.

59. Dixon, R.A.; Xie, D.-Y.; Sharma, S.B. Proanthocyanidins-A final frontier in flavonoid research? New Phytol. 2005, 165, 9-28.

60. Heller, W.; Forkmann, G. Biosynthesis of flavonoids. In Flavonoids: Advances in Research since 1986; Harborne, J.B., Ed.; Chapman and Hall: London, UK, 1994; pp. 499-535.

61. Forkmann, G.; Heller, W. Biosynthesis of flavonoids. In Comprehensive Natural Products Chemistry; Barton, D., Nakanishi, K., Meth-Cohn, O., Eds.; Elsevier: Amsterdam, The Netherlands, 1999; pp. 713-748.

62. Asen, S. Identification of flavonoid chemical markers in roses and their high pressure liquid chromatographic resolution and quantitation for cultivar identification. J. Am. Soc. Hort. Sci. 1982, 107, 744-750.

63. Asen, S.; Griesbach, R. HPLC analysis of flavonoids in Geranium florets as an adjunct for cultivar identification. J. Amer. Soc. Hort. Sci. 1983, 108, 845-850.

64. Asen, S. HPLC analysis of flavonoid chemical markers in petals from Gerbera flowers as an adjunct for cultivar and germplasm identification. Phytochemistry 1984, 23, 2523-2526.

65. van Sumere, C.F.; vande Casteele, K.; de Loose, R.; Heursel, J. Reversed phase-HPLC analysis of flavonoids and the biochemical identification of cultivar of evergreen Azalea. In Biochemistry of Plant Phenolics; van Sumere, C.F., Lea, P.J., Eds.; Clarendon Press: Oxford, UK, 1985; pp. $17-43$.

66. Treutter, D.; Feucht, W. Art- and klonspezifische polyphenolmuster des phloems von Prunus avium and Prunus cerasus. Mitt. Klosterneuburg 1985, 35, 256-260. 
67. Treutter, D.; Feucht, W. Zur chemotaxonomie von süßkirschensorten. Schwei . Z. Obst. Weinbau 1985, 121, 391-394.

68. Martelock, G.; Bauer, H.; Treutter, D. Characterization of Prunus avium L. varieties with phenolic compounds. Fruit Var. J. 1994, 48, 81-88.

69. Geibel, M.; Treutter, D.; Meier, N. Characteriszation of sour cherries by HPLC-analysis of the bark-fölavonoids combined with multivariate statistics. Euphytica 1990, 45, 229-235.

70. Bauer, H.; Treutter, D. Identification of Pelargonium genotypes by phenolic 'fingerprints'. II. Cultivar identification by HPLC analysis of leaf phenols combined with discriminant analysis. Gartenbauwiss 1990, 55, 187-191.

71. Groh, B.; Bauer, H.; Treutter, D. Chemotaxonomical investigations of Prunus domestica by isoenzyme markers and phenolic compounds. Sci. Hort. 1994, 58, 41-55.

72. Makris, D.P.; Kallithraka, S.; Mamalos, A. Differentiation of young red wines based on cultivar and geographical origin with application of chemometrics of principal polyphenolic constituents. Talanta 2006, 70, 1143-1152.

73. Avar, P.; Pour Nikfardjam, M.S.; Kunsági-Máté, S.; Montskó, G.; Szabó, Z.; Böddi, K.; Ohmacht, R.; Márk, L. Investigation of phenolic components of hungarian wines. Int. J. Mol. Sci. 2007, 8, 1028-1038.

74. Stoll, K. Der Apfel; Enrico Negri AG: Zürich, Switzerland. 1997.

75. Ju, Z.; Liu, C.;Yuan, Y.; Wang, Y.; Liu, G. Coloration potential, anthocyanin accumulation, and enzyme activity in fruit of commercial apple cultivars and their F1 progeny. Sci. Hort. 1999, 79, $39-50$.

76. Awad, M.A.; Wagenmakers, P.S.; deJager, A.Effects of light on flavonoids and chlorogenic acid levels in the skin of 'Jonagold' apples. Sci. Hort. 2001, 88, 289-298.

77. Solovchenko, A.; Schmitz-Eiberger, M. Significance of skin flavonoids for UV-B-protection in apple fruits. J. Exp. Bot. 2003, 54, 1977-1984.

78. Merzlyak M.N.; Solovchenko, A.E.; Smagin, A.I.; Gitelson A.A. Apple flavonols during fruit adaptation to solar radiation: Spectral features and technique for non-destructive assessment. $J$. Plant Physiol. 2005, 162, 151-160.

79. Hagen, S.F.; Borge, G.I.A.; Bengtsson, G.B.; Bilger, W.; Berge, A.; Haffner, K.; Solhaug, K.A. Phenolic contents and other health and sensory related properties of apple fruit (Malus domestica Borkh., cv. Aroma): Effect of postharvest UV-B irradiation. Postharv. Biol. Technol. 2007, 45, $1-10$.

80. Hohl, U.; Neubert, B.; Pforte, H.; Schonhof, I.; Böhm, H. Flavonoid concentrations in the inner leaves of head lettuce genotypes. Eur. Food Res. Technol. 2001, 213, 205-211.

81. Oh, M.-M.; Carey, E.E.; Rajashekar, C.B. Environmental stresses induce health-promoting phytochemicals in lettuce. Plant Physiol. Biochem. 2009, 47, 578-583.

82. Paolocci, F.; Bovone, T.; Tosti, N.; Arcioni, S.; Damiani, F. Light and an exogenous transcription factor qualitatively and quantitatively affect the biosynthetic pathway of condensed tannins in Lotus corniculatus leaves. J. Exp. Bot. 2005, 56, 1093-1103.

83. Kim, E.H.; Kim, S.H.; Chung, J.I.; Chi, H.Y.; Kim, J.A.; Chung, I.M. Analysis of phenolic compounds and isoflavones in soybean seeds (Glycine max (L.) Merill) and sprouts grown under different conditions. Eur. Food Res. Technol. 2006, 222, 201-208. 
84. Peña-Neira, A.; Cáceres, A.; Pastenes, C. Low molecular weight phenolic and anthocyanin composition of grape skins from cv. syrah (Vitis vinifera L.) in the Maipo Valley (Chile): Effect of clusters thinning and vineyard yield. Food Sci. Technol. Int. 2007, 13, 153-159.

85. Anttonen, M.J.; Karjalainen, R.O. Environmental and genetic variation of phenolic compounds in red raspberry. J. Food Compos Anal. 2005, 18, 4565-4570.

86. Wang, S.Y.; Chen, C.-T.; Wang, C.Y. The influence of light and maturity on fruit quality and flavonoid content of red raspberries. Food Chem. 2009, 112, 676-684.

87. Arakawa, O.; Hori, Y.; Ogata, R. Relative effectiveness and interaction of ultraviolet-B, red and blue light in anthocyanin synthesis of apple fruit. Physiol. Plant 1985, 64, 323-327.

88. Lancaster, J.E. Regulation of skin color in apple. Crit. Rev. Plant Sci. 1992, 10, 487-502.

89. García-Macías P.; Ordidge, M.; Vysini, E.;Waroonphan, S.;Battey, N.; Gordon, M.H.; Hadley, P.; John, P.; Lovegrove, J.; Wagstaffe, A. Lettuce cultivation under plastic films varying in ultraviolet transparency. J. Agric. Food Chem. 2007, 55, 10168-10172.

90. Romani, A.; Pinelli, P.; Galardi, C.; Sani, G.; Cimato, A.; Heimler, D. Polyphenols in greenhouse and open-air-grown lettuce. Food Chem. 2002, 79, 337-342.

91. Keski-Saari, S.; Pusenius, J.; Julkunen-Tiitto, R. Phenolic compounds in seedlings of Betula pubescens and $B$. pendula are affected by enhancing UVB radiation and different nitrogen regimes during early ontogeny. Glob. Change Biol. 2005, 11, 1180-1194.

92. Kolb, C.A.; Kopecký, J.; Riederer, M.; Pfündel, E.E. UV screening by phenolics in berries of grapevine (Vitis vinifera). Funct. Plant Biol. 2003, 30, 1177-1186.

93. Ryan, K.G.; Markham, K.R.; Bloor, S.J.; Bradley, J.M.; Mitchell, K.A.; Jordan, B.R. UVB radiation induced increase in quercetin: Kaempferol ratio in wild-type and transgenic lines of Petunia. Photochem. Photobiol. 1998, 68, 323-330.

94. Blankenship, S.M. Night-temperature effects on rate of apple fruit maturation and fruit quality. Sci. Hort. 1987, 33, 205-212.

95. Mori, K.; Sugaya, S.; Gemma, H. Decreased anthocyanin biosynthesis in grape berries grown under elevated night temperature condition. Sci. Hort. 2005. 105, 319-330.

96. Wang, S.Y.; Zheng, W. Effect of plant growth temperature on antioxidant capacity in strawberry. J. Agric. Food Chem. 2001, 49, 4977-4982.

97. Oh, M.-M.; Trick, H.N.; Rajashekar, C.B. Secondary metabolism and antioxidants are involved in environmental adaptation and stress tolerance in lettuce. J. Plant Physiol. 2009, 166, 180-191.

98. Lo Piero, A.R.; Puglisi, I.; Rapisarda, P.; Petrone G. Anthocyanins accumulation and related gene expression in red orange fruit induced by low temperature storage. J. Agric. Food Chem. 2005, 53, 9083-9088.

99. Lattanzio, V. Bioactive polyphenols: Their role in quality and storability of fruit and vegetables. J. Appl. Bot. 2003, 77, 128-146.

100. Engelsma, G.A. possible role of divalent manganese ions in the photoinduction of phenylalanine ammonia-lyase. Plant Physiol. 1972, 50, 599-602.

101. Durst, F. The correlation of phenylalanine ammonia-lyase and cinnamate 4-hydroxylase activity in Jerusalem artichoke tuber tissue. Planta 1976, 132, 221-227.

102. van Brederode, J.; van Genderen, H.H.; Berendsen, W. Morphological effects of the flavones isovitexin in a non-glycosylating genotype of Silene pratensis. Experientia 1982, 38, 929-931. 
103. Kutsuki, H.; Shimada, Y.; Higuchi, T. Distribution and role of p-hydroxycinnamate:CoA ligase in lignin biosynthesis. Phytochemistry 1982, 21, 267-271.

104. Bassim, T.A.H.; Pecket, R.C. The effect of membrane stabilizers on phytochrome-controlled anthocyanin biosynthesis in Brassica oleraceae. Phytochemistry 1975, 14, 731-733.

105. Lipetz, J. Calcium and lignifications in tissue culture. Am. J. Bot. 1962, 49, 460-464.

106. Yuri, A.; Schmitt, E.; Feucht, W.; Treutter, D. Metabolism of Prunus tissues affected by $\mathrm{Ca}^{2+}$ deficiency and addition of prunin. J. Plant Physiol. 1990, 135, 692-697.

107. Koeppe, D.E.; Southwick, L.M.; Bitell, J.E. The relationship of tissue chlorogenic acid concentrations and leaching of phenolics from sunflowers grown under varying phosphate nutrient conditions. Can. J. Bot. 1976, 54, 593-599.

108. Zornoza, P.; Esteban, R.M. Flavonoids content of tomato plants for the study of the nutritional status. Plant Soil 1984, 82, 269-271.

109. Shkolnik, M.Y. Trace Elements in Plants; Elsevier: Amsterdam, The Netherlands, 1984.

110. Feucht, W.; Treutter, D.; Bengsch, E.; Polster J. Efects of watersoluble boron and aluminium compounds on the synthesis of flavanols in grape vine callus. Z. Naturforsch. 1999, 54c, 942-945.

111. Nørbæk, R.; Aaboer, D.B.F.; Bleeg, I.S.; Christensen, B.T.; Kondo, T.; Brandt, K. Flavone Cglycoside, phenolic acid, and nitrogen contents in leaves of barley subject to organic fertilization treatments. J. Agric. Food Chem. 2003, 51, 809-813.

112. Radi, M.; Mahrouz, M.; Jaouad, A.; Amiot, M.J. Influence of mineral fertilization (NPK) on the quality of apricot fruit (cv. Canino). The effect of the mode of nitrogen supply. Agronomie 2003, 23, 737-745.

113. Matros, A.; Amme, S.; Kettig, B.; Buck-Sorlin, G.H.; Sonnewald, U.; Mock, H.P. Growth of elevated $\mathrm{CO}_{2}$ concentrations leads to modified profiles of secondary metabolites in tobacco cv. SamsunNN and to increases resistance against infection with potato virus Y. Plan, Cell Environ. 2006, 29, 126-137.

114. Blodgett, J.T.; Bonello, P.; Herms, D.A. Fertilization decreases resistance of red pine to the Sphaeropsis canker pathogen. Phytopathology 2003, 93 (Suppl. 6), S9.

115. Saxon, M.E.; Davis, M.A.; Pritchard, S.G.; Runion, G.B.; Prior, S.A.; Stelzer, H.E.; Rogers, H.H.; Dute, R.R. Influence of elevated $\mathrm{CO}_{2}$, nitrogen, and Pinus elliotti genotypes on performance of the redheaded pine sawfly Neodiprion lecontei. Can. J. Forest Res. 2004, 34, 1007-1017.

116. Witzell, J.; Shevtsova, A. Nitrogen-induced changes in phenolics of Vaccinium myrtillusImplications for interaction with a parasitic fungus. J. Chem. Ecol. 2004, 30, 1937-1956.

117. Stewart, A.J.; Chapman, W.; Jenkins, I.; Graham, I.; Martin, T.; Crozier, A. The effect of nitrogen and phosphorus deficiency on flavonol accumulation in plant tissue. Plant Cell Environ. 2001, 24, 1189-1197.

118. Muzika, R.M.; Pregitzer, K.S. Effect of nitrogen fertilization on leaf phenolic production of grand fir seedlings. Trees-Struct. Funct. 1992, 6, 241-244.

119. Kainulainen, P.; Utriainen, J.; Holopainen, J.K.; Oksanen, J.A.R.I.; Holopainen, T. Influence of elevated ozone and limited nitrogen availability on conifer seedlings in an open-air fumigation system: Effects on growth, nutrient content, mycorrhiza, needle ultrastructure, starch and secondary compounds. Glob. Change Biol. 2000, 6, 345-355. 
120. Bahlsberg Pahlsson, A. Influence of nitrogen fertilization on minerals, carbohydrates, amino acids and phenolic compounds in beech (Fagus sylvatica L.) leaves. Tree Physiol. 1992, 10, 93-100.

121. Hakulinen, J.R.; Julkunen-Tiitto, R.; Tahvanainen, J. Does nitrogen fertilization have an impact on the trade-off between willow growth and defensive secondary metabolism? Trees-Struct. Funct. 1995, 9, 235-240.

122. Lavola, A.; Julkunen-Tiitto, R. The effect of elevated carbon dioxide and fertilization on the primary and secondary metabolites in birch Betula pendula (Roth). Oecologia 1994, 99, $315-321$.

123. Keinänen, M.; Julkunen-Tiitto, R. Highperformance liquid chromatographic determination of flavonoids in Betula pendula and Betula pubescens leaves. J. Chrom. A 1998, 793, 370-377.

124. Keinänen, M.; Julkunen-Tiitto, R.; Mutikainen, P.; Walls, M.; Ovaska, J.; Vapaavuori, E. Tradeoffs in phenolic metabolism of silver birch: Effects of fertilization, defoliation, and genotype. Ecology 1999, 80, 1970-1986.

125. Keski-Saari, S.; Julkunen-Tiitto, R. Resource allocation in different parts of juvenile mountain birch plants: effect of nitrogen supply on seedling phenolics and growth. Physiol. Plant. 2003, $118,114-126$.

126. Keski-Saari, S.; Pusenius, J.; Julkunen-Tiitto, R. Phenolic compounds in seedlings of Betula pubescens and $B$. pendula are affected by enhanced UVB radiation and different nitrogen regimens during early ontogeny. Glob. Change Biol. 2005, 11, 1180-1194.

127. Mittelstraß, K.; Treutter, D.; Pleßl, M.; Heller, W.; Elstner, E.F.; Heiser, I. Modification of primary and secondary metabolism of potato plants by nitrogen application differentially affects resistance to Phytophthora infestans and Alternaria solani. Plant Biol. 2006, 8, 653-661.

128. Awad, M.A.; de Jager, A. Relationships between fruit nutrients and concentrations of favonoids and chlorogenic acid in 'Elstar' apple skin. Sci. Hort. 2002, 92, 265-276.

129. Leser, C.; Treutter, D. Effects of nitrogen supply on growth, contents of phenolic compounds and pathogen (scab) resistance of apple trees. Physiol. Plant. 2005, 123, 49-56.

130. Wang, S.Y.; Zheng, W.; Galletta, G.J. Cultural system affects fruit quality and antioxidant capacity in strawberries. J. Agric. Food Chem. 2002, 50, 6534-6542.

131. Wang, S.Y.; Lin, H.-S. Compost as a soil supplement increases the level of antioxidant compounds and oxygen radical absorbance capacity in strawberries. J. Agric. Food Chem. 2003, 51, 6844-6850.

132. Anttonen, M.J.; Hoppula, K.I.; Nestby. R.; Verheul, M.L.J.; Karjalainen, R.O. Influence of fertilization, mulch color, early forcing, fruit order, planting date, shading, growing environment, and genotype on the contents of selected phenolics in strawberry (Fragaria x ananassa Duch.) Fruits. J. Agric. Food Chem. 2006, 54, 2614-2620.

133. Cipollini, M.L.; Paulk, E.; Cipollini, D.F. Effect of nitrogen and water treatment on leaf chemistry in horsenettle (Solanum carolinense), and relationship to herbivory by flea beetles (Epitrix spp.) and tobacco hornworm (Manduca sexta). J. Chem. Ecol. 2002, 28, 2377-2398.

134. Sørensen, C.; Truelsen, E. Chemical composition of barley varieties with different nutrient supplies. I. Concentration of nitrogen, tannins, phytate, $\beta$-glucans and minerals. Tidsskr. Planteavl. 1985, 89, 253-261. 
135. Harms, H. Phenolstoffwechsel in pflanzen in abhängigkeit von stickstoffform und -angebot. Landwirtsch. Forsch. 1983, 36, 9-18.

136. Westcott, R.J.; Henshaw, G.G. Phenolic synthesis and phenylalanine ammonia-lyase activity in suspension cultures of Acer pseudoplatanus. Planta 1976, 131, 67-73.

137. Yamakawa, T.; Kato, S.; Ishida, K.; Kodamen, T.; Minoda, Y. Production of anthocyanins by Vitis cells in suspension culture. Agr. Biol. Chem. 1983, 47, 2185-2191.

138. Faust, M. Physiology of anthocyanin development in McIntosh apple. II. Relationship between protein synthesis and anthocyanin development. Prod. Am. Soc. Hort. Sci. 1965, 87, 10-20.

139. Parker, J. Relationship among cold hardiness, water soluble proteins, anthocyanins and free sugars in Hedera helix. Plant Physiol. 1962, 37, 809-813.

140. Margna, U. Control at the level of substrate supply-an alternative in the regulation of phenylpropanoid accumulation in plant cells. Phytochemistry 1977, 16, 419-426.

141. Margna, U.; Vainjärv, T.; Laanest, L. Different L-phenylalanine pools avaiable for the biosynthesis of phenolics in buckwheat seeding tissues. Phytochemistry 1989, 28, 469-475.

142. Margna, U. Role of different metabolic sources of L-phenylalanine in the biosynthesis of flavonoids. Acta Horticult. 1994, 381, 185-191.

143. Scheible, W.-R.; Morcuende, R.; Czechowski, T.; Fritz, C.; Osuna, D.; Palacios-Rojas, N.; Schindelasch, D.; Thimm, O.; Udvardi, M. K.; Stitt, M. Genome-wide reprogramming of primary and secondary metabolism, protein synthesis, cellular growth processes, and the regulatory infrastructure of Arabidopsis in response to nitrogen. Plant Physiol. 2004, 136, 2483-2499.

144. Fritz, C.; Palacios-Rojas, N.; Feil, R.; Stitt, M. Regulation of secondary metabolism by the carbon-nitrogen status in tobacco: Nitrate inhibits large sectors of phenylpropanoid metabolism. Plant J. 2006, 46, 533-548.

145. Bongue-Bartelsman, M.; Phillips, D.A. Nitrogen stress regulates gene expression of enzymes in the flavonoid biosynthetic pathway of tomato. Plant Physiol. Biochem. 1995, 33, 539-546.

146. Lillo, C.; Lea, U.S.; Ruoff, P. Nutrient depletion as a key factor for manipulating gene expression and product formation in different branches of the flavonoid pathway. Plant Cell Environ. 2008, 31, 587-601.

147. Tan, S.C. Phenylalanine ammonia-lyase and the phenylalanine ammonia-lyase inactivating system: Effects of light, temperature and mineral deficiencies. Aust. J. Plant Physiol. 1980, 7, $159-167$.

148. Strissel, T.; Halbwirth, H.; Hoyer, U.; Zistler, C.; Stich, K.;Treutter, D. Growth-promoting nitrogen nutrition affects flavonoid biosynthesis in young apple (Malus domestica Borkh.) leaves. Plant biol. 2005, 7, 677-685.

149. Dixon, R.A.; Paiva, N.L. Stress-lnduced phenylpropanoid metabolism. Plant Cell 1995, 7, 1085-1097.

150. Feucht, W.; Treutter, D. The role of flavan-3-ols and proanthocyanidins in plant defence. In Principles and Practices in Plant Ecology; Inderjit, S., Dakshini, K., Foy, C.L., Eds.; CRC Press: Boca Raton, FL, USA, 1999; pp. 307-338.

151. Treutter, D. Significance of flavonoids in plant resistance and enhancement of their biosynthesis. Plant Biol. 2005, 7, 581-591. 
152. Krauss, S.; Graßmann, J.; Woitke, M.; Schnitzler, W.H. The influence of elevated ec-levels in the nutrient solution on post harvest quality of tomatoes. Acta Horticult. 2007, 741, 189-197.

153. Duteau, J.; Guilloux, M.; Sguin, G. Influence des facteurs naturels sur la maturation du raisin, en 1979, à Pomerol et Saint-Emilion. Connaiss. Vigne Vin. 1981, 15, 1-27.

154. Piretti, M.V.; Serrazanetti, G.P.; Pistore, R. Influence of seasonal beaviousr on the polyphenolic constituents of Vitis vinifera grape. Ann. Chim. 1980, 70, 615-624.

155. Esteban, M.A.; Villanueva, M.J.; Lissarrague, J.R. Effect of irrigation on changes in the anthocyanin composition of the skin of cv. Tempranillo (Vitis vinifera $\mathrm{L}$ ) grape berries during ripening. J. Sci. Food Agric. 2001, 81, 409-420.

156. Cohen, Y.; Treutter, D.; Feucht, W. Water stress induced changes in phenol composition of leaves and phloem of Prunus avium L. Acta Horticult. 1994, 381, 494-497.

157. Gruppe, W. Evaluating orchard behavior of cherry rootstocks. Acta Horticult. 1985, 169, 199-208.

158. Tubbs, F.R. Tree size control through dwarfing rootstocks. Proc. XVII. Int. Hort. Congr. III, 1967, 43-56.

159. Lockard, R.G. Schneider W Stock and scion relationships and the dwarfing mechanism in apple. Hort. Res. 1981, 3, 315-375.

160. Stevens, G.A.; Westwood, M.N. Fruit set and cytokinin-like activity in the xylem sap of sweet cherry (P. avium) as affected by rootstock. Physiol. Plant. 1984, 61, 464-468.

161. Treutter, D.; Feucht, W.; Schmid, P.P.S. Polyphenole des phloems in beziehung zur inkompatibilität von interspezifischen prunus-veredlungen (Prunus avium L., Prunus cerasus L.). I. Flavanone und flavanole über der veredlungsstelle. Gartenbauwissenschaft 1986, 51, 77-84.

162. Treutter, D. Polyphenole des phloems in beziehung zur inkompatibilität von interspezifischen Prunus-Veredlungen (Prunus avium L., Prunus cerasus L.). II. Akkumulation von p-cumaroylglucose über der veredlungsstelle. Gartenbauwiss 1989, 54, 261-264.

163. Treutter, D.; Feucht, W. Accumulation of phenolic compounds above the graft union of cherry trees. Gartenbauwiss 1991, 56, 134-137.

164. Errea, P.; Treutter, D.; Feucht, W. Characterization of flavanol-type polyphenols in apricot cultivar and rootstock. Adv. Hort. Sci. 1994, 8, 165-169.

165. Feucht, W.; Schmid, P.P.S.; Christ, E. Kompatibilität bei Prunus avium/Prunus cerasusVeredlungen während der Verwachsungsphase. I. Struktur des Phloems einschließlich der Siebröhren. Gartenbauwiss 1983, 48, 45-50.

166. Treutter, D.; Galensa, R.; Feucht, W.; Schmid, P.P.S. Flavanone glucosides in callus and phloem of Prunus avium: Identification and stimulation of their synthesis. Physiol. Plant. 1985, 65, 95-101.

167. Feucht, W.; Treutter, D.; Schmid, P.P.S. Inhibition of growth and xylogenesis and promotion of vacuolation in Prunus callus by the flavanone prunin. Plant Cell Rep. 1988, 7, 189-192.

168. Bauer, H.; Treutter, D.; Schmid, P.P.S.; Schmitt, E.; Feucht, W. Specific accumulation of odiphenols in stressed leaves of Prunus avium. Phytochemistry 1989, 28, 1363-1364. 
169. Gil-Izquierdo, A.; Riquelme, M.T.; Porras, I.; Ferreres, F. Effect of the rootstock and interstock grafted in lemon tree (Citrus limon (L.) Burm.) on the flavonoid content of lemon juice. J. Agric. Food Chem. 2004, 52, 324-331.

170. Bindi, M.; Fibbi, L.; Miglieta, F. Free air $\mathrm{CO}_{2}$ enrichment (FACE) of grapevine (Vitis vinifera L.): II. Growth and quality of grape and wine in response to elevated $\mathrm{CO}_{2}$ concentrations. Eur. $J$. Agron. 2001, 14, 145-155.

171. Wang, S.Y.; Bunce, J.A.; Maas, J.L. Elevated carbon dioxide increases contents of antioxidant compounds in field-grown strawberries. J. Agric. Food Chem. 2003, 51, 4315-4320.

172. Kuokkanen, K.; Julkunen-Titto, R.; Keinanen, M.; Niemela, P.; Tahvanainen, J. The effect of elevated $\mathrm{CO}_{2}$ and temperature on the secondary chemistry of Betula pendula seedlings. Trees 2001, 15, 378-384.

173. Saxon, M.E.; Davis, M.A.; Pritchard, S.G.; Runion, G.B.; Prior, S.A.; Stelzer, H.E.; Rogers, H.H.; Dute, R.R. Influence of elevated $\mathrm{CO}_{2}$, nitrogen, and Pinus elliotti genotypes on performance of the redheaded pine sawfly Neodiprion lecontei. Can. J. Forest Res. 2004, 34, 1007-1017.

174. Castells, E.; Roumet, C.; Peñuelas, J.; Roy, J. Intraspecific variability of phenolic concentrations and their responses to elevated $\mathrm{CO}_{2}$ in two mediterranean perennial grasses. Environ. Exp. Bot. 2002, 47, 205-216.

175. Davey, M.P.; Bryant, D.N.; Cummins, I.; Ashenden, T.W.; Gates, P.; Baxter, R.; Edwards, R. Effects of elevated $\mathrm{CO}_{2}$ on the vasculature and phenolic secondary metabolism of Plantago maritima. Phytochemistry 2004, 65, 2197-2204.

176. Coley, P.D.; Massa, M.; Lovelock, C.E.; Winter, K. Effects of elevated $\mathrm{CO}_{2}$ on foliar chemistry of saplings of nine species of tropical tree. Oecologia 2002, 133, 62-69.

177. Tattini, M.; Galardi, C.; Pinelli, P.; Massai, R.; Rumorini, D.; Agati, G. Differential accumulation of flavonoids and hydroxycinnamates in leaves of Ligustrum vulgare under excess light and drought stress. New Phytol. 2004, 163, 547-561.

178. Peltonen, P.A.; Vapaavuori, E.; Julkunen-Tiitto, R. Accumulation of phenolic compounds in birch leaves is changed by elevated carbon dioxide and ozone. Glob. Change Biol. 2005, 11, 1305-1324.

179. Holton, K.; Lindroth, R.L.; Nordheim, E.V. Foliar quality influences tree-herbivore-parasitoid interactions: Effect of elevated $\mathrm{CO}_{2}, \mathrm{O}_{3}$, and plant genotype. Oecologia 2003, 137, 233-244.

180. Mayr, U.; Treutter, D.; Santos-Buelga, C.; Bauer, H.; Feucht, W. Developmental changes in the phenol concentrations of 'Golden delicious' apple fruits and leaves. Phytochemistry 1995, 38, 1151-1155.

181. Halbwirth, H.; Puhl, I.; Haas, U.; Jezik, K.; Treutter, D.; Stich, K. Two-phase flavonoid formation in developing strawberry (Fragaria x ananassa) fruit. J. Agric. Food Chem. 2006, 1479-1485.

182. Jaakola, L.; Määttä, K.; Pirttilä, A.M.; Törrönen, R.; Kärenlampi, S.; Hohtola, A. Expression of genes involved in anthocyanin biosynthesis in relation to anthocyanin, proanthocyanidin, and flavonol levels during bilberry fruit development. Plant Physiol. 2002, 130, 729-739.

183. Wang, S.Y.; Chen, C.-T.; Wang, C.Y. The influence of light and maturity on fruit quality and flavonoid content of red raspberries. Food Chem. 2009 112, 676-684. 
184. Treutter, D.; Feucht, W.; Schmid, P.P.S. Ageing-dependent responses of phloem flavonoids of Prunus avium graftings: Flavanone-, flavone- and isoflavone-glucosides. Sci. Hort. 1987, 32, 183-193.

185. Feucht, W.; Treutter, D.; Polster, J. Flavanol binding of nuclei from tree species. Plant Cell Rep. 2004, 22, 430-436.

186. Gould, K.; Lister, C. Flavonoid functions in plants. In Flavonoids. Chemistry, Biochemistry and Applications; Andersen, O.M., Markham, K.R., Eds.; Taylor and Francis: Boca Raton, FL, USA, 2005; pp. 397-442.

187. Kolb, C.A.; Käser, M.A.; Kopecký, J.; Zotz, G.; Riederer, M.; Pfündel, E.E. Effects of natural intensities of visible and ultraviolet radiation on epidermal ultraviolet screening and photosynthesis in grape leaves. Plant Physiol. 2001, 127, 863-875.

188. Edwards, W.R.; Hall, J.A.; Rowlan, A.R.; Schneider-Barfield, T.; Sun, T.J.; Patil, M.A.; Pierce, M.L.; Fulcher, R.G.; Bell, A.A.; Essenberg, M. Light filtering by epidermal flavonoids during the resistant response of cotton to Xanthomonas protects leaf tissue from light-dependet phytoalexin toxicity. Phytochemistry 2008, 69, 2320-2328.

189. El-Kereamy, A.; Chervin, C.; Souquet, J.; Moutounet, M.; Monje, M.; Nepveu, F.; Mondies, H.; Ford, C.M.; Heeswijck, R.; Roustan, J. Ethanol triggers grape gene expression leading to anthocyanin accumulation during berry ripening. Plant Sci. 2002, 163, 449-454.

190. del Río, J.A.; Báidez, A.G.; Botía, J.M.; Ortuno, A. Enhancement of phenolic compounds in olice plants (Olea europaea L.) and their influence on resistance against Phytophthora sp. Food Chem. 2003, 83, 75-78.

191. Botia, J.M.; Ortuno, A.; Benavente-Garcia, O.; Baidez, A.G.; Frias, J.; Marcos, D.; del R1o J. A. Modulation of the biosynthesis of some phenolic compounds in Olea europaea L. fruits: Their influence on olive oil quality. J. Agric. Food Chem. 2001, 49, 355-358.

192. Ortuno, A.; Botia, J.M.; Fuster, M.D.; Porras, I.; Garcia-Lidon A.; del Rio J.A. Effect of scoparone (6,7-Dimethoxycoumarin) biosynthesis on the resistance of tangelo nova, Citrus paradisi, and Citrus aurantium fruits against Phytophthora parasitica. J. Agric. Food Chem. 1997, 45, 2740-2743.

193. Fofana, B.; McNally, D.J.; Labbe, C.; Boulanger, R.; Benhamou, N.; Seguin, A.; Belanger, R.R. Milsana-induced resistance in powdery mildew-infected cucumber plants correlates with the induction of chalcone synthase and chalcone isomerase. Physiol. Molec. Plant Pathol. 2002, 61, 121-132.

194. McNally, D.J.; Wurms, K.V.; Labbe, C.; Belanger, R.R. Synthesis of C-glycosyl flavonoid phytoalexins as a site-specific response to fungal penetration in cucumber. Physiol. Molec. Plant Pathol. 2003, 63, 293-303.

195. Fofana, B.; Benhamou, N.; McNally, D.J.; Labbé, C.; Séguin, A.; Bélanger, R.R. Suppression of induced resistance in cucumber through disruption of the flavonoid pathway. Phytopathology 2005, 95, 114-123.

196. Mayr, U.; Batzdorfer, R.; Treutter, D.; Feucht, W. Surfactant-induced changes in penol content of apple leaves after wounding. Acta Horticult. 1994, 381, 479-487.

197. Hino, F.; Okazaki, M.; Miura, Y. Effects of kinetin on formation of scopoetin and scopolin in tobacco tissue cultures. Agric. Biol. Chem. 1982, 46, 2195-2201. 
198. Ranjeva, R.; Boudet, A.M.; Harada, H.; Marigo, G. Phenolic metabolism in petunia tissues. I. Characteristic responses of enzymes involved in different steps of polyphenol synthesis to different hormonal influence. Biochem. Biophys. Acta 1975, 399, 23-30.

199. Shah, R.R.; Subbaiah, K.V.; Mehta, A.R. Hormonal effect on polyphenol accumulation in Cassia tissue cultured in vivo. Can. J. Bot. 1976, 54, 1240-1245.

200. Margna, U.; Vainjärv, T. Kinetin-mediated stimulation of accumulation of buckwheat flavonoids in the dark. Z. Naturforsch. C 1983, 38, 711-716.

201. Klein, A.O.; Hagen, C.W. Anthocyanin production in detached petas of Impatiens balsamina L. Plant Physiol. 1961, 36, 1-9.

202. Shulman, Y.; Lavee, S. The effect of cytokinins and auxins on anthocyanin accumulation in green Manzanillo olives. J. Exp. Bot. 1973, 24, 655-661.

203. Straub, V.; Lichtenthaler, H.K. Effect of gibberellic acid $\mathrm{GA}_{3}$ and kinetin on formation of photosynthetic pigments, lipoquinones, and anthocyanins in Raphanus seedlings. $Z$. Pflanzenphysiol. 1973, 70, 308-321.

204. Pecket, R.C.; Bassim, T.A.H. The effect of kinetin in relation to photocontrol of anthocyanin biosynthesis in Brassica oeracea. Phytochemistry 1974, 13, 1395-1399.

205. Nakamae, H.; Nakamura, N. Effects of metabolic inhibitors on anthocyanin accumulation in petals of Rosa hybrida Hort. Plant Cell. Pysiol. 1983, 24, 995-1002.

206. Treutter, D.; Feucht, W. Taxonomicaly relevant flavonoid glycosides of Prunus phloem and their response according to various physiological conditions. Bull. Group Polyphén 1986, 13, 45-49.

207. Teszlák, P.; Gaál, K.; Pour Nikfardjam, M.S. Influence of grapevine flower treatment with gibberellic acid $\left(\mathrm{GA}_{3}\right)$ on polyphenol content of Vitis vinifera L. wine. Anal. Chim. Acta 2005, $543,275-281$.

208. Schmitz, M.; Seitz, U. Hemmung der anthocyansynthese durch gibberellinsäure $\mathrm{A}_{3}$ bei kalluskulturen von daucus carota. Z. Pflanzenphysiol. 1972, 68, 259-265.

209. Daines, R.J.; Minocha, S.C.; Kudakasseril, G.L. Induction of penylalanine-ammonia-lyase in germinating lettuce seeds (Lactuca sativa). Physiol. Plant 1983, 59, 134-140.

210. Hinderer, W.; Petersen, M.; Seitz, H.U. Inibition of flavonoid biosynthesis by gibberellic acid in cell suspension cultures of Daucus carota L. Planta 1984, 160, 544-549.

211. Barnes, L.; Jones, R.L. Regulation of phenylalanine ammonia-lyase activity and growth in lettuce by light and gibberellie acid. Plant Cell Environ. 1984, 7, 89-95.

212. Hyodo, H.; Yang, S.F. Ethylene-enhanced synthesis of phenylalanine-ammonia-lyase in pea seedlings. Plant Physiol. 1971, 47, 765-770.

213. Abeles, F.B. Ethylene in Plant Biology; Springer, New York, NY, USA, 1973.

214. Wong, P.P.; Zucker, M.; Creasy, L.C. Induction of PAL in strawberry leaf discs. Plant Physiol. 1974, 54, 659-665.

215. Rhodes, J.M.; Wooltorton, L.S.C. The biosynthesis of phenolic compounds in wounded plant storage tissues. In: Biochemistry of Wounded Plant Tissue; Kahl, G., Ed.; Walter de Gruyter \& Co.: Berlin, Germany, 1978; pp. 243-286.

216. Craker, L.E.; Wetherbee, P.J. Ethylene, carbon dioxide, and anthocyanin synthesis. Plant Physiol. 1973, 52, 177-179. 
217. Craker, L.E. Effect of ethylene and metabolic inhibitors on anthocyanin biosynthesis. Phytochemistry 1975, 14, 151-153.

218. Faragher, J.D.; Brohier, R.L. Anthocyan accumulation in apple skin durin ripening: Regulation by ethylene and phenylalanine ammonia-lyase. Sci. Hort. 1984, 22, 89-96.

219. Li, Z.H.; Gemma, H.; Iwahori, S. Stimulation of 'Fuji' apple skin color by ethephon and phosphorus-calcium mixed compounds in relation to flavonoid synthesis. Sci. Hort. 2002, 94, 193-199.

220. Golding, J.B.; Wang, Z.; Dilley, D.R. Effects of MCP and light on postharvest colour development in apples. Acta Horticult. 2003, 600, 85-89.

221. Arakawa, O.; Hori, Y.; Ogata, R. Relative effectiveness and interaction of UV-B red and blue light in anthocyanin synthesis of apple Malus pumila cultivar 'Jonathan' fruit. Physiol. Plant. 1985, 64, 323-327.

222. Mozetič, B.; Simčič, M.; Trebš, P. Anthocyanins and hydroxycinnamic acids of Lambert Compact cherries (Prunus avium L.) after cold storage and 1-methylcyclopropene treatment. Food Chem. 2006, 97, 302-309.

223. Wang, S.Y.; Zheng, W. Preharvest application of methyl jasmonate increases fruit quality and antioxidant capacity in raspberries. Int. J. of Food Sci. Technol. 2005, 40, 187-195.

224. Fumagalli, F.; Rossoni, M.; Iriti, M.; Di Gennaro, A.; Faoro, F.; Borroni, E.; Borgo, M.; Scienza, A.; Sala, A. ; Folco, G. From field to health: A simple way to increase the nutraceutical content of grape as shown by NO-dependent vascular relaxation. J. Agric. Food Chem. 2006, 54, 5344-5349.

225. Lo, Giudice, D.; Wolf, T.K.; Zoecklein, B.W. Effects of prohexadione-calcium on grape yield components and fruit and wine composition. Am. J. Enol. Vitic. 2004, 55, 73-83.

226. Rademacher, W. Growth retardants: Effects on gibberellin biosynthesis and other metabolic pathways. Annu. Rev. Plant Physiol. Plant Mol. Biol. 2000, 51, 501-531.

227. Römmelt, S.; Treutter, D.; Speakman, J.B.; Rademacher, W. Effects of prohexadione-Ca on the flavonoid metabolism of apple with respect to plant resistance against fire blight. Acta Hortic. 1999, 489, 359-364.

228. Römmelt, S.; Zimmermann, N.; Rademacher, W.; Treutter, D. Formation of novel flavonoids in apple (Malus $\times$ domestica) treated with the 2-oxoglutarate-dependent dioxygenase inhibitor prohexadione-Ca. Phytochemistry 2003, 64, 709-716.

229. Schlangen, K.; Gosch, C.; Roemmelt, S.; Knott, J.; Fischer, T.C.; Treutter, D.; Forkmann, G.; Stich, K.; Halbwirth, H. Can prohexadione-Ca induce antimicrobial flavonoids in rose? Europ. J. Hort. Sci. 2003, 68, 137-143.

230. Gosch, C.; Puhl, I.; Halbwirth, H.; Schlangen, K.; Römmelt, S.; Andreotti, C.; Costa, G.; Fischer, T.C.; Treutter, D.; Stich, K.; Forkmann, G. Effect of prohexadione-Ca on various fruit crops: Flavonoid composition and substrate specificity of their dihydroflavonol 4-reductases. Eur. J. Hortic. Sci. 2003, 68, 144-151.

231. Halbwirth, H.; Fischer, T.C.; Roemmelt, S.; Spinelli, F.; Schlangen, K.; Peterek, S.; Sabatini, E.; Messina, C.; Speakman, J.-B.; Andreotti, C.; Rademacher, W.; Bazzi, C.; Costa, G.; Treutter, D.; Forkmann, G.; Stich K. Induction of antimicrobial 3-Deoxyflavonoids in pome fruit trees controls fire blight. Z. Naturforsch. 2003, 58c, 765-770. 
232. Fischer, T.C.; Halbwirth, H.; Roemmelt, S.; Sabatini, E.; Schlangen, K.; Andreotti, C.; Spinelli, F.; Costa, G.; Forkmann, G.; Treutter, D.; Stich, K. Induction of polyphenol gene expression in apple (Malus $\times$ domestica) after the application of a dioxygenase inhibitor. Physiol. Plant 2006, $128,604-617$.

233. Spinelli, F.; Speakman, J.-B.; Rademacher, W.; Halbwirth, H.; Stich, K.; Costa, G. Luteoforol, a flavan 4-ol, is induced in pome fruits by prohexadione-calcium and shows phytoalexin-like properties against Erwinia amylovora and other plant pathogens. Eur. J. Plant Pathol. 2005, 112, $133-142$.

234. Römmelt, S.; Fischer, T.C.; Halbwirth, H.; Peterek, S.; Schlangen, K.; Speakman, J.-B.; Treutter, D.; Forkmann, G.; Stich, K. Effect of dioxygenase inhibitors on the resistance-related flavonoid metabolism of apple and pears: Chemical, biochemical and molecular biological aspects. Eur. J. Hortic. Sci. 2003, 68, 129-136.

235. Puhl, I.; Treutter, D. Ontogenetic variation of catechin biosynthesis as basis for infection and quiescence of Botrytis cinerea in developing strawberry fruits. J. Plant Dis. Prot. 2008, 115, 247-251.

236. Vasconsuelo, A.; Boland, R. Molecular aspects of the early stages of elicitation of secondary metabolites in plants. Plant Sci. 2007, 172, 861-875.

237. Faust, M. Physiology of anthocyanin development in McIntosh apple. I. Participation of pentose phosphate pathway in anthocyanin development. Proc. Am. Soc. Hort. Sci. 1965, 87, 1-9.

238. Lux-Endrich, A.; Treutter, D.; Feucht, W. Influence of nutrients and carbohydrate supply on the phenol composition of apple shoot cultures. Plant Cell Tissue Organ Cult. 2000, 60, 15-21.

239. Carter, E.B.; Theodorou, M.K.; Morris, P. Responses of Lotus corniculatus to environmental change. 2. Effect of elevated $\mathrm{CO}_{2}$, temperature and drought on tissue digestion in relation to condensed tannin and carbohydrate accumulation. J. Sci. Food Agric. 1999, 79,1431-1440.

240. Matyssek, R.; Schnyder, H.; Munch, J.-C.; Oßwald, W.; Pretzsch, H.; Treutter, D. Resource Allocation in Plants-The Balance between Resource Sequestration and Retention. Plant Biol. 2005, 7, 557-559.

241. Gianfagna, T.J.; Berkowitz G.A. Glucose catabolism and anthocyanin production in apple fruit. Phytochemistry 1986, 25, 607-610.

242. Lattanzio, V.; Kroon, P.A.; Quideau, S.; Treutter, D. Introduction: Plant Phenolics-Secondary Metabolites with Diverse Functions. In Recent Advances in Polyphenol Research; Daayf, F., Lattanzio, V., Eds.; Wiley-Blackwell: Chichester, UK, 2008; Volume 1, pp. 1-35.

243. Shetty, K. Role of proline-linked pentosae phosphate pathway in biosynthesis of plant phenolics for functional food and environmental applications: A review. Proc. Biochem. 2004, 9, 789-803.

244. Lattanzio, V.; Cardinali, A.; Ruta, C.; Fortunato, I.M.; Lattanzio, V.M.T.; Linsalata, V.; Cicco, N. Relationship of secondary metabolism to growth in oregano (Origanum vulgare L.) shoot cultures under nutritional stress. Environ. Exp. Bot. 2009, 65, 54-62.

245. Kutchan, T.M. A role for intra- and intercellular translocation in natural product biosynthesis. Curr. Opin. Plant Biol. 2005, 8, 1-9.

246. Jørgensen, K.; Rasmussen, A.V.; Morant, M.; Nielsen, A.H.; Bjarnholt, N.; Zagrobelny, M.; Bak, S.; Lindberg-Møller, B. Metabolon formation and metabolic channeling in the biosynthesis of plant natural products. Curr. Opin. Plant Biol. 2005, 8, 1-12. 
247. Grotewold, E. The genetics and biochemistry of floral pigments. Annu. Rev. Plant Biol. 2006, 57, 761-780.

248. Koes, R.; Verweij, W.; Quattrocchio, F. Flavonoids: A colorful model for the regulation and evolution of biochemical pathways. Trends Plant Sci. 2005, 10, 236-242.

249. Shimada, N.; Sasaki, R.; Sato, S.; Kaneko, T.; Tabata, S.; Aoki, T.; Ayabe, S. A comprehensive analysis of six dihydroflavonol 4-reductases encoded by a gene cluster of the Lotus japonicus genome. J. Exp. Bot. 2005, 56, 2573-2585.

250. Pang, Y.; Peel, G.J.; Wright, E.; Wang, Z.; Dixon, R.A. Early steps in proanthocyanidin biosynthesis in the model legume Medicago truncatula. Plant Physiol. 2007, 145, 601-615.

251. Paolocci, F.; Robbins, M.P.; Madeo, L.; Arcioni, S.; Martens, S.; Damiani, F. Ectopic expression of a basic helix-loop-helix gene transactivates parallel pathways of proanthocyanidin biosynthesis. Structure, expression analysis, and genetic control of leucoanthocyanidin 4reductase and anthocyanidin reductase genes in Lotus corniculatus. Plant Physiol. 2007, 143, 504-516.

252. Davies, K.M.; Schwinn, K.E. Transcriptional regulation of secondary metabolism. Funct. Plant Biol. 2003, 30, 913-925.

253. Rowan, D.D.; Cao, M.; Lin-Wang, K.; Cooney, J.M.; Jensen, D.J.; Austin, P.T.; Hunt, M.B.; Norling, C.; Hellens, R.P.; Schaffer, R.J.; Allan, A.C. Environmental regulation of leaf colour in red 35S:PAP1Arabidopsis thaliana. New Phytol. 2009, 182, 102-115.

254. Gonzalez, A. Pigment loss in response to the environment: A new role for the WD/bHLH/MYB anthocyanin regulatory complex. New Phytol. 2009, 182, 1-3.

255. Lepiniec, L.; Debeaujon, I.; Routaboul, J.-M.; Baudry, A.; Pourcel, L.; Nesi, N.; Caboche, M. Genetics and biochemistry of seed flavonoids. Annu. Rev. Plant Biol. 2006, 57, 405-430.

256. Dubos, C.; Le Gourrierec, J.; Baudry, A.; Huep, G.; Lanet, E.; Debeaujon, I.; Routaboul, J.-M.; Alboresi, A.; Weisshaar, B.; Lepiniec, L. MYBL2 is a new regulator of flavonoid biosynthesis in Arabidopsis thaliana. Plant J. 2008, 55, 940-953.

257. Broun, P. Transcriptional control of flavonoid biosynthesis: A complex network of conserved regulators involved in multiple aspects of differentiation in Arabidopsis. Curr. Opin. Plant Biol. 2005, 8, 272-279.

258. Aharoni, A.; de Vos, C.H.R.; Wein, M.; Sun, Z.; Greco, R.; Kroon, A.; Mol, J.N.M.; O'Connell, A.P. The strawberry FaMYB1 transcription factor suppresses anthocyanin and flavonol accumulation in transgenic tobacco. Plant J. 2001, 28, 319-332.

259. Matsui, K.; Umemura, Y.; Ohme-Takagi, M. AtMYBL2, a protein with a single MYB domain, acts as a negative regulator of anthocyanin biosynthesis in Arabidopsis. Plant J. 2008, 55, 954-967.

260. Honda, C.; Kotoda, N.; Wada, M.; Kondo, S.; Kobayashi, S.; Soejima, J.; Zhang, Z.; Tsuda, T.; Moriguchi, T. Anthocyanin biosynthetic genes are coordinately expressed during red coloration in apple skin. Plant Physiol. Biochem. 2002, 40, 955-962.

261. Takos A.M.; Ubi, B.E.; Robinson, S.P.; Walker, A.R. Condensed tannin biosynthesis genes are regulated separately from other flavonoid biosynthesis genes in apple fruit skin. Plant Sci. 2006, $170,487-499$. 
262. Espley, R.V.; Hellens, R.P.; Putterill, J.; Stevenson, D.E.; Kutty-Amma, S; Allan, A.C. Red colouration in apple fruit is due to the activity of the MYB transcription factor, MdMYB10. Plant J. 2007, 49, 414-427.

263. Dong, Y.; Mitra, D.; Lister, C.; Lancaster, J.; Kootstra, A. Postharvest stimulation of skin color in Royal Gala apple. J. Am. Soc. Hort. Sci. 1995, 120, 95-100.

264. Ubi, B.E.; Honda, C.; Bessho, H.; Kondo, S.; Wada, M.; Kobayashi, S.; Moriguchi T. Expression analysis of anthocyanin biosynthetic genes in apple skin: Effect of UV-B and temperature. Plant Sci. 2006, 170, 571-578.

265. Ban, Y.; Honda, C.; Hatsuyama, Y.; Igarashi, M.; Bessho, H.; Moriguchi, T. Isolation and functional analysis of a MYB transcription factor gene that is a key regulator for the development of red coloration in apple skin. Plant Cell Physiol. 2007, 48, 958-970.

266. Boss, P.K.; Davies, C.; Robinson, S.P. Expression of anthocyanin biosynthesis pathway genes in red and white grapes. Plant Mol. Biol. 1996, 32, 565-569.

267. Kobayashi, S.; Ishimaru, M.; Hiraoka, K.; Honda, C. Myb-related genes of the Kyoho grape (Vitis labruscana) regulate anthocyanin biosynthesis. Planta 2002, 215, 924-933.

268. Deluc, L.; Barrieu, F.; Marchive, C.; Lauvergeat, V.; Decendit, A.; Richard, T.; Carde, J.P.; Merillon, J.M.; Hamdi. S. Characterization of a grapevine R2R3-MYB transcription factor that regulates the phenylpropanoid pathway. Plant Physiol. 2006, 140, 499-511.

269. Gerats, A.G.M.; de Vlaming, P. ; Doodeman, M.; Al, B.; Schram, A.W. Genetic control of the conversion of dihydroflavonols into flavonols and anthocyanins in flowers of Petunia hybrida. Planta 1982, 155, 364-368.

270. Bohm, B. The minor flavonoids. In Flavonoids: Advances in Research since 1986; Harborne, J.B., Ed.; Chapman \& Hall: London, UK, 1994; pp. 329-388.

271. Forkmann, G. Flavonoids as flower pigments: The formation of the natural spectrum ad its extension by genetic engineering. Plant Breed. 1991, 106, 1-26.

272. Forkmann, G. Genetics of flavonoids. In The Flavonoids; Harborne, J.B., Ed.; Chapman and Hall: London, UK, 1993; pp. 537-564.

273. Heller, W.; Forkmann, G. Biosynthesis. In The Flavonoids: Advances in Research; Harborne, J.B., Ed.; Chapman and Hall: London, UK, 1988; pp. 399-425.

274. Davies, K.; Schwinn, K.E. Molecuar biology and biotechnology of flavonoid biosynthesis. In Flavonoids. Chemistry, Biochemistry and Applications; Andersen, Ø.M., Markham, K.R., Eds.; Taylor and Francis: Boca Raton, FL, USA, 2005; pp. 143-218.

275. Forkmann, G. Control of pigmentation in natural and transgenic plants. Curr. Opin. Biotechnol. 1993, 4, 159-165.

276. Forkmann, G.; Martens, S. Metabolic engineering and applications of flavonoids. Curr. Opin. Biotechnol. 2001, 12, 155-160.

277. Schijlen, E.G.W.M.; de Vos, C.H.R.; van Tunen, A.J.; Bovy, A.G. Modification of flavonoid biosynthesis in crop plants. Phytochemistry 2004, 65, 2631-2648.

278. Tanaka, Y.; Ohmiya, A. Seeing is believing: Engineering anthocyanin and carotenoid biosynthetic pathways. Curr. Opin. Biotechnol. 2008, 19, 190-197. 
279. Muir, S.R.; Collins, G.J.; Robinson, S.; Hughes, S.; Bovy, A.; de Vos, C.H.R.; van Tunen, A.J.; Verhoeyen, M.E. Overexpression of petunia chalcone isomerase in tomato results in fruit containing increased levels of flavonols. Nat. Biotechnol. 2001, 19, 470-474.

280. Bovy, A.; de Vos, R.; Kemper, M.; Schijlen, E.; Almenar Pertejo, M.; Muir, S.; Collins, G.; Robinson, S.; Verhoeyen, M.; Hughes, S.; Santos-Buelga, C.; van Tunen, A. High-flavonol tomatoes resulting from the heterologous expression of the maize transcription factor genes $L C$ and C1. Plant Cell 2002, 14, 2509-2526.

281. Butelli, E.; Titta, L.; Giorgio, M.; Mock, H.-P.; Matros, A.; Peterek, S.; Schijlen, E.G.W.M.; Hall, R.D.; Bovy, A.G.; Luo, J.; Martin, C. Enrichment of tomato fruit with health-promoting anthocyanins by expression of select transcription factors. Nat. Biotechnol. 2008, 26, 1301-1308.

282. Davuluri, G.R.; van Tuinen, A.; Fraser, P.D.; Newman, R.; Burgess, D.; Brummell, D.A.; King, S.R.; Palys, J.; Uhlig, J.; Bramley, P.M.; Pennings. H.M.J.; Bowle, C. Fruit-specific RNAimediated suppression of DET1 enhances carotenoid and flavonoid content in tomatoes. Nat. Biotechnol. 2005, 23, 890-895.

283. Shih, C.-H.; Chen, Y.; Wang, M.; Chu, I.K.; Lo, C. Accumulation of isoflavone genistin in transgenic tomato plants overexpressing a soybean isoflavone synthase gene. J. Agric. Food Chem. 2008, 56, 5655-5661.

284. Stobiecki, M.; Matysiak-Kata, I.; Franski, R.; Skala, J.; Szopa, J. Monitoring changes in anthocyanin and steroid alkaloid glycoside content in lines of transgenic potato plants using liquid chromatography/mass spectrometry. Phytochemistry 2003, 62, 959-969.

285. Szankowski, I.; Briviba, K.; Fleschhut, J.; Schönherr, J.; Jacobsen, H.J.; Kiesecker, H. Transformation of apple (Malus domestica Borkh.) with the stilbene synthase gene from grapevine (Vitis Vinifera L.) and a PGIP gene from kiwi (Actinidia deliciosa). Plant Cell Rep. 2003, 22, 141-149.

286. Rühmann, S.; Treutter, D.; Fritsche, S.; Briviba, K.; Szankowski, I. Piceid (resveratrol glucoside) synthesis in stilbene synthase transgenic apple fruit. J. Agric. Food Chem. 2006, 54, 4633-4640.

287. Meyer, P.; Heidemann, I.; Forkmann, G.; Saedler, H. A new petunia flower colour generated by transformation of a mutant with a maize gene. Nature 1987, 330, 677-678.

288. Fukui, Y.; Yoshikazu, T.; Takaaki, K.; Takashi, I.; Kyosuke, N. A rationale for the shift in colour towards blue in transgenic carnation flowers expressing the flavonoid 3',5'-hydroxylase gene. Phytochemistry 2003, 63, 15-23.

289. Davies, K.M.; Schwinn, K.E.; Deroles, S.C.; Manson, D.G.; Lewis, D.H.; Bloor, S.J.; Bradley, J.M. Enhancing anthocyanin production by altering competition for substrate between flavonol synthase and dihydroflavonol 4-reductase. Euphytica 2003, 131, 259-268.

290. Nielsen, A.H.; Olsen, C.E.; Lindberg-Møller, B. Flavonoids in flowers of 16 Kalanchoë blossfeldiana varieties. Phytochemistry 2005, 66, 2829-2835.

291. Rosati, C.; Simoneau, P.; Treutter, D.; Poupard, P.; Cadot, Y.; Cadic, A.; Duron, M. Engineering of flower color in forsythia by expression of two independently-transformed dihydroflavonol 4reductase and anthocyanidin synthase genes of flavonoid pathway. Mol. Breed. 2003, 12, 197-208.

292. Xie, D.-Y.; Sharma, S.B.; Paiva, N.L.; Ferreira, D.; Dixon, R.A. Role of anthocyanin reductase, encoded by BANYULS in plant flavonoid biosynthesis. Science 2003, 299, 396-399. 
293. Gutterson, N.C. Molecular breeding for color, flavor and fragrance. Horticult. Sci. 1993, 55, 141-160.

294. Treutter, D. Biosynthesis of phenolic compounds and its regulation in apple. Plant Growth Regul. 2001, 34, 71-89.

295. Alonso-Salces, R.M.; Herrero, C.; Barranco, A.; Berrueta. L.A.; Gallo, B.; Vicente, F. Classification of apple fruits according to their maturity state by the pattern recognition analysis of their polyphenolic compositions. Food Chem. 2005, 93, 113-123.

296. Willits, M.G.; Kramer, C.M.; Prata, R.T.N.; DeLuca, V.; Potter, B.G.; Steffens, J.C.; Graser, G. Utilization of the genetic resources of wild species to create a nontransgenic high flavonoid tomato. J. Agric. Food Chem. 2005, 53, 1231-1236.

297. Howard, L.R.; Clark, J.R.; Brownmiller, C. Antioxidant capacity and phenolic content in blueberries as affected by genotype and growing season. J. Sci. Food Agric. 2003, 83, 1238-1247.

298. Kassim, A.; Poette, J.; Paterson, A.; Zait, D.; McCallum, S.; Woodhead, M.; Smith, K.; Hackett, C.; Graham, J. Environmental and seasonal influences on red raspberry anthocyanin antioxidant contents and identification of quantitative traits loci (QTL). Mol. Nutr. Food Res. 2009, 53, $625-634$.

299. Wang, S.Y.; Stretch, A.W. Antioxidant capacity in cranberry is influenced by cultivar and storage temperature. J. Agric. Food Chem. 2001, 49, 969-974.

300. Siriwoharn, T.; Wrolstad, R.E.; Finn, C.E.; Pereira, C.B. Influence of cultivar, maturity, and sampling on blackberry (Rubus L. Hybrids) anthocyanins, polyphenolics, and antioxidant properties. J. Agric. Food Chem. 2004, 52, 8021-8030.

301. Howard, L.R.; Pandjaitan, N.; Morelock, T.; Gil, M.I. Antioxidant capacity and phenolic content of spinach as affected by genetics and growing season. J. Agric. Food Chem. 2002, 50, 5891-5896.

302. Ölschläger, C.; Regos, I.; Zeller, F.J.; Treutter, D. Identification of galloylated propelargonidins and procyanidins in buckwheat grain and quantification of rutin and flavanols from homostylous hybrids originating from F. esculentum x F. homotropicum. Phytochemistry 2008, 69, 1389-1397.

303. Steyn, W.J.; Wand, S.J.E.; Holcroft, D.M.; Jacobs, G. Anthocyanins in vegetative tissues: A proposed unified function in photoprotection. New Phytol. 2002, 155, 349-361.

304. Gould, K.S. Nature's swiss army knife: The diverse protective roles of anthocyanins in leaves. $J$. Biomed. Biotechnol. 2004, 5, 314-320.

305. Bednarek, P.; Osbourn, A. Plant-microbe interactions: Chemical diversity in plant defense. Science 2009, 324, 746-748.

306. Pennycooke, J.C.; Cox, S.; Stushnoff, C. Relationship of cold acclimation, total phenolic content and antioxidant capacity with chilling tolerance in petunia (Petunia $\times$ hybrida). Environ. Exp. Bot.. 2005, 53, 225-232.

307. Puhl, I.; Stadler, F.; Treutter, D. Alterations of flavonoid biosynthesis in young grapevine (Vitis vinifera $\mathrm{L}$.) leaves, flowers, and berries induced by the dioxygenase inhibitor prohexadione-Ca. J. Agric. Food Chem. 2008, 56, 2498-2504.

308. Rühmann, S.; Leser, C.; Bannert, M.; Treutter, D. Relationship between growth, secondary metabolism, and resistance of apple. Plant Biol. 2002, 4, 137-143. 
309. Rühmann, S.; Treutter, D. Effect of N-nutrition in apple on the response of its secondary metabolism to prohexadione-Ca treatment. Eur. J. Hortic. Sci. 2003, 68, 152-159.

310. Keller, M.; Rogiers, S.Y.; Schultz, H.R. Nitrogen and ultraviolet radiation modify grapevines' susceptibility to powdery mildew. Vitis $\mathbf{2 0 0 3}, 42,87-94$.

311. Fries, K. Phenole und Wachstum. Beitr. Biol. Pfl. 1968, 44, 289-318.

312. Kefeli, V.I.; Kutacek, M. Penolic substances and their possible role in plant growth regulation. In Plant Growth Regulator Abstracts; Pilet, P.E., Ed.; CABI: Surrey, UK, 1977; pp. 181-188.

313. James, D.J.; Thurbon, I.J. Phenolic compounds and other factors controlling rhizogenesis in vivo in the apple rootstocks M9 and M26. Z. Pflanzenphysiol. 1981, 105, 11-20.

314. Ray, S.D.; Guruprasad, K.N.; Laloraya, M.N. Antagonistic action of phenolic compounds on abscisic acid induced inhibition of hypocotyls growth. J. Exp. Bot. 1980, 31, 1651-1656.

315. Hendershott, C.H.; Walker, D.R. Identification of a growth inhibitor from extracts of dormant peach flower buds. Science 1959, 130, 798-799.

316. Corgan, J.N. Identification of pruning (naringenin 7-glucoside) in dormant peach buds as a wheat coleoptiles growth inhibitor. Hort. Sci. 1967, 2, 105-106.

317. Erez, A.; Lavee, S. Prunin identification, biological activity and quantitative change in comparison to naringenin in domant peach buds. Plant Physiol. 1969, 44, 342-346.

318. Nitsch, J.P.; Nitsch, C. Composés phenoliques et croissance végétale. Ann. Physiol. Vég. 1962, 4, 211-225.

319. Vargna, M.; Köves, E. Effect of phenolic compounds on the activity of indoleacetic acid oxidase. Naturwiss 1962, 49, 355-356.

320. Stenlid, G. The effect of flavonoid compounds on oxidative phosphorylation and on enzymic destruction of indoleacetic acid. Physiol. Plant. 1963, 16, 110-120.

321. Feucht, W.; Schmid, P.P.S. Effect of orthodihydroxyphenols on growth and protein pattern of callus cultures from Prunus avium. Physiol. Plant. 1980, 50, 309-313.

322. Feucht, W.; Treutter, D. Catechin effects on growth related processes in cultivated calli of Prunus avium. Gartenbauwiss 1995, 60, 7-11.

323. Volpert, R.; Osswald, W.; Elstner, E.F. Effects of cinnamic acid derivatives on indole acetic acid oxidation by peroxidase. Phytochemistry 1995, 38, 19-22.

324. Lavee, S.; Avidan, N.; Pierik, R.L.M. Chlorogenic acid-an independent morphogenesis regulator or a cofactor. Acta Horticult. 1994, 381, 405--412.

325. Feucht, W.; Treutter, D.; Keukenkamp, I. Growth enhancement of grapevine callus by catechin on auxin-free media. Vitis 1998, 37, 67-71.

326. Peer, W.A.; Murphy, A.S. Flavonoids and auxin transport: Modulators or regulators? Trends Plant Sci. 2007, 12, 556-563.

327. Stenlid, G. Effects of flavonoids on the polar transport of auxin. Physiol. Plant. 1977, 38, 262-266.

328. Stenlid, G. Flavonoids as inhibitors of the formation of adenosine triposphate in plant mitochondria. Phytochemistry 1970, 9, 2251-2256.

329. Feucht, W.; Dithmar, H.; Polster, J. Variation of the nuclear, subnuclear and chromosomal flavanol deposition in Hemlock and Rye. Int. J. Mol. Sci. 2004, 8, 635-650. 
330. Feucht, W.; Treutter, T.; Dithmar, H.; Polster, J. Microspore development of three coniferous species: Affinity of nuclei for flavonoids. Tree Physiol. 2008, 28, 1783-1791.

331. Saslowsky, D.E.; Warek, U.; Winkel, B.S.J. Nuclear localization of flavonoid enzymes in Arabidopsis. J. Biol. Chem. 2005, 280, 23735-23740.

332. Feucht, W.; Dithmar, H.; Polster, J. Nuclei of Taxus baccata: Flavanols linked to chromatin remodeling factors. J. Bot. 2009, 2009, 842869:1-842869:9.

333. Treutter, D.; Feucht, W. Accumulation of phenolic compounds above the graft union of cherry trees. Gartenbauwiss 1991, 56, 134-137.

334. Feucht, W.; Treutter, D. Phenol gradients in opposing cells of Prunus heterografts. Adv. Hort. Sci. 1991, 5, 107-111.

335. Dirr, U.; Feucht, W.; Treutter, D. Effect of nutrient deficiency on accumulation and leakage of the stress metabolite prunin. Acta Horticult. 1994, 381, 398-404.

336. Feucht, W.; Treutter, D. Effects of abscisic acid and (+)-catechin on growth and leaching properties of callus from four fruit tree species. Gartenbauwiss 1996, 61, 174-178.

337. Feucht, W.; Treutter, D.; Christ, E. Role of flavanols in yellowing beech trees of the Black Forest. Tree Physiol. 1997, 17, 335-340.

338. Feucht, W.; Treutter, D.; Christ, E. Flavanols in grapevine: In vitro accumulation and defence reactions in shoots. Vitis 1996, 35, 113-118.

339. Field, B.; Jordán, F.; Osbourn, A. First encounters-deployment of defence-related natural products by plants. New Phytol. 2006, 172, 193-207.

340. Dakora, F.D. Defining new roles for plant and rhizobial molecules in sole and mixed plant cultures involving symbiotic legumes. New Phytol. 2003, 158, 39-49.

341. Hungria, M.; Stacey, G. Molecular signals exchanged between host plants and rhizobia: Basic aspects and potential application in agriculture. Soil Biol. Biochem. 1997, 29, 819-830.

342. Broughton, W.J.; Zhang, F.; Perret, X. Signals exchanged between legumes and Rhizobium: Agricultural uses and perspectives. Plant Soil 2003, 252, 129-137.

343. Mathesius, U. Conservation and divergence of signalling pathways between roots and soil microbes - the Rhizobium-legume symbiosis compared to the development of lateral roots, mycorrhizal interactions and nematode-induced galls. Plant Soil 2003, 255,105-119.

344. Mathesius, U.; Schlamann, H.R.M.; Spaink, H.P.; Sautter, C.; Rolfe, B.C.; Djordjevic, M.A. Auxin transport inhibition precedes root nodule formation in white clover roots and is regulated by flavonoids and derivatives of chitin oligosaccharides. Plant J. 1998, 14, 23-24.

345. Kobayashi, H.; Naciri-Graven, Y.; Broughton, W.J.; Perret, X. Flavonoids induce temporal shifts in gene-expression of nod-box controlled loci in Rhizobium sp. NGR234. Mol. Microbiol. 2004, $51,335-347$.

346. Webster, G.; Jain, V.; Davey, M.R.; Gough, C.; Vasse, J.; Dénarié, J.; Coking, E.C. The flavonoid naringenin stimulates the intercellular colonization of wheat roots by Azorhizobium caulinodans. Plant Cell Environ. 1998, 21, 373-383.

347. Benoit, L.F.; Berry, A.M. Flavonoid-like compounds from seeds of red alder (Alnus rubra) influence host nodulation by Frankia (Actinomycetales). Physiol. Plant. 1997, 99, 588-593. 
348. Ponce, M.A.; Scervino, J.M.; Erra-Balsells, R.; Ocampo, J.A.; Godeas, A.M. Flavonoids from shoots and roots of Trifolium repens (white clover) grown in presence or absence of the arbuscular mycorrhizal fungus Glomus intraradices. Phytochemistry 2004, 65, 1925-1930.

349. Harrison, M.J.; Dixon, R.A. Spatial pattern of expression of flavonoid/isoflavonoid pathway genes during interactions between roots of Medicago trunculata and the mycorrhizal fungus Glomus versiforme. Plant J. 1994, 6, 9-20.

350. Lagrange, H.; Jay-Allemand, C.; Lapeyrie, F. Rutin, the phenolglycoside from eucalyptus root exudates, stimulates Pisolithus hyphal growth at picomolar concentrations. New Phytol. 2001, 149, 349-355.

351. Wirth, H.; Lechtenböhmer, H.J. Verbraucher testen neue apfelsorten. Obstbau 1984, 9, 366-368.

352. Zech, J. Apfel-Neuheiten im verbrauchertest. Obstbau 1989, 14, 209-214.

353. Iglesias, I.; Echeverria, G.; Soria, Y. Differences in fruit colour development, anthocyanin content, fruit quality and consumer acceptability of eight 'Gala' apple strains. Sci. Hort. 2008, $115,40-46$.

354. Anonym. Durchschnittliche auszahlungspreise für golden delicious 1190-2002. ObstbauWeinbau 2003, 40, 69-72.

355. Janßen, H. Apfelsortenwahl am bodensee aus der sicht des marktes. Obstbau 1986, 11, 278-281

356. Goodrie, P.D. Bewertung von jonagold-mutanten. Obstbau 1991, 16, 361-364.

357. Silbereisen, R. Entwicklung im apfelsortiment. Obstbau 1993, 18, 24-28.

358. Stehr, R.; Clever, M. Rote mutanten von jonagold. Obstbau 1995, 20, 432-436.

359. Stehr, R.; Clever, M. Rote mutanten von elstar. Obstbau 1995, 20, 482-485.

360. Baab, G. Braeburn-eine sorte für profis. Obstbau 1996, 21, 330-335.

361. Fischer, M. 'Pinova' zeigt farbe. Obstbau 2005, 30, 614.

(C) 2010 by the authors; licensee Molecular Diversity Preservation International, Basel, Switzerland. This article is an open-access article distributed under the terms and conditions of the Creative Commons Attribution license (http://creativecommons.org/licenses/by/3.0/). 